\title{
CÓRDOBA EN LAS "MINUTAS CARTOGRÁFICAS" DEL INSTITUTO GEOGRÁFICO NACIONAL (1871-1900) Y SU HÁBITAT RURAL COMO HERRAMIENTA CARTOGRÁFICA
}

\author{
Martín Torres-Márquez \\ Departamento de Geografía y Ciencias del Territorio. Universidad de Córdoba \\ martin.torres@uco.es
}

\section{RESUMEN}

El señalado valor paisajístico y patrimonial del poblamiento rural está fuera de toda duda. La amplia bibliografía ha puesto de manifiesto la importancia de los pueblos, cortijos, caseríos y haciendas en el contexto de la España rural. Pero esa infinidad de valores ha de completarse con el significado que el hábitat rural adquirió en los orígenes de la cartografía contemporánea. En el presente estudio examinamos, de forma suscita, la perspectiva técnica de la construcción cartográfica y topográfica de finales del siglo XIX, así como su estrecha relación con el hábitat rural como recurso cartográfico en la primera serie topográfica 1:50.000 del Instituto Geográfico. Para ello recurrimos a los itinerarios topográficos realizados entre 1871 y 1893 y a sus resultados en las "minutas cartográficas" para una muestra municipal de la provincia de Córdoba: La Carlota, Conquista, Fernán Núñez, Palma del Río, Valsequillo y Zuheros. Las deducciones concluyentes aspiran a ser un veraz ejemplo del significado cartográfico del hábitat rural como herramienta para el desarrollo de la primera cartografía topográfica cordobesa y española.

Palabras clave: hábitat rural; cartografía histórica; técnicas cartográficas; topografía; Córdoba; Andalucía.

\section{ABSTRACT \\ Cordoba in the Spanish Geographic Institute "Cartographic Notes" (1871-1900) and its rural habitat as a cartographic tool}

The importance of the rural landscape and heritage is absolutely manifest. A great deal of academic literature highlights the significance of all sorts of rural settlements in Spain such as villages, cortijos (rural housing typical of the southernmost part of Spain), caseríos (small rural settlements formed of a few houses) and haciendas (rural estates surrounded by cattle and cultivated land.) However, these numerous values should be complemented with an acknowledgement of the meaning acquired by the rural habitat at the dawn of contemporary cartography. The aim of this study is to examine the technical perspective of the cartographic and topographic construction of the late $19^{\text {th }}$ century, together with the relationship between the latter and the rural habitat as a cartographic resource in the first 1:50.000 topographic series of Spain’s National Geographic Institute. In this study, topographic itineraries designed between 1871 and 1893 have been consulted, as well as the results found in the minutas or "cartographic notes" for a selection of some of the municipalities in the province of Córdoba such as La Carlota, Conquista, Fernán Núñez, Palma del Río, Valsequillo and Zuheros. The final conclusions drawn from this research aspire to lay the foundations for a verified example of the cartographic meaning of the rural habitat as a tool for the development of the first topographic cartography of Córdoba and of Spain.

Keywords: rural habitat; historical cartography; cartographic technologies; topography; Córdoba; Andalucía; Andalusia.

\section{INTRODUCCIÓN}

Entre las múltiples fórmulas de las que disponemos para representar los cambios territoriales y paisajísticos de un determinado espacio geográfico, la cartografía ha sido, posiblemente, el recurso que, 
mediante el uso de códigos gráficos, convencionalismos y toponimia, mejor ha plasmado la objetividad del perceptor y también que con más eficacia ha posibilitado la aprehensión, el acercamiento, la sucesiva planificación y ordenación de los territorios y lugares.

Pero esa construcción cartográfica, sobre todo desde la óptica técnica, no ha sido siempre la misma ni, por supuesto, ha gozado de los mismos materiales y herramientas para su elaboración. Desde las primeras representaciones paisajísticas cartografiadas, con ejemplos como el conocido "mapa" hallado en la cueva de Abauntz (Arraitz, Navarra), fechado hace unos 13.660 años (Utrilla, Mazo, Sopena, Martínez-Beas y Domingo, 2009), hasta la más reciente evolución tecnológica, la ciencia cartográfica ha ido sumando nuevas herramientas, materiales y tecnologías que han mejorado la capacidad humana para representar con fidelidad la superficie terrestre. Pero, con todo, desde la más antigua expresión hasta la más reciente innovación digital (Moreno, 2004; Metternicht, 2006), todas tienen en común la necesidad de situar y representar el espacio geográfico con propósitos exploratorios, demográficos, políticos, económicos, militares, sociales, etc.

Y también esa evolución de las herramientas cartográficas ha modelado y articulado la propia imagen del territorio y sus paisajes, pues la sociedad que crea una cartografía no hace sino imprimir en el espacio geográfico su propia concepción de los lugares, facilitando su comprensión, su gestión y uso. Pero, en paralelo, esa construcción gráfica incide, mediante su lectura, en la propia idea que del territorio se posee y que se construye sincrónica y diacrónicamente.

Es, lo que para muchos, constituye lo que se conoce como el "Poder de los Mapas", capaces de recoger los caracteres cualitativos y cuantitativos de un territorio y su sociedad; y también capaz de modelar y construir, desde argumentos y propósitos variopintos, la propia identidad territorial de sus habitantes (Quam, 1943; Ager, 1977; Claval, 1978; Wood, 1992; o Núñez de las Cuevas, 2012).

En esa narración gráfica y toponímica del mapa, en sus diversas expresiones históricas y técnicas, los protagonistas son los accidentes naturales, las construcciones geopolíticas y administrativas, o la expresión tangible, y también intangible, de la presencia y la actividad humana acumulada en el tiempo y el espacio.

\section{LAS DEFICIENCIAS CARTOGRÁFICAS EN LA SEGUNDA MITAD DEL XIX}

A pesar de los esfuerzos por modernizar la realidad cartográfica, los proyectos del siglo XVIII y primera mitad del XIX adolecían de la inexistencia de profesionales cualificados, falta de experiencia y, sobre todo, del uso de un sistema de medidas caótico y desigual entre los territorios. Y a ello se sumaba la escasa densidad de unas infraestructuras territoriales que facilitaran la traslación planimétrica y altimétrica a los formatos cartográficos.

Ni siquiera los ilustrados del XVIII, aquéllos que declaraban la "necesidad del Mapa" (Paladini, 1991), alcanzaron a confeccionar una verdadera serie cartográfica homogénea. Campos y ciudades, con muy contadas excepciones, eran espacios cartográficamente ignotos y, aunque no faltaron iniciativas que perseguían reconducir la situación o solventarla localmente (Martín, 1986; Hernando, 1996), habrá que aguardar a la segunda mitad del XIX, tras la Guerra de Independencia y la instauración de los primeros sistemas constitucionales (Núñez de las Cuevas, 1982), para que se inicie la primera serie cartográfica del territorio nacional, publicándose en 1875 la hoja de Madrid del Mapa Topográfico Nacional 1:50.000.

Los planteamientos abordados a mediados del XVIII por el marqués de la Ensenada y Jorge Juan Santisicilia ${ }^{1}$, o los llevados a cabo poco después por Tomás López de Vargas Machuca, o no fructificaron o se tradujeron en ejercicios cartográficos "de gabinete"; proceder, éste último, que restringía de forma sustancial los resultados y que ocasionaba graves equivocaciones planimétricas. Y tales iniciativas no fueron las únicas, pues durante la segunda mitad del XVIII y primeras décadas del XIX se repitieron numerosos intentos por mejorar la deficiente cartografía española, así como por incrementar la información estadística y catastral que de sus territorios se poseía (Nadal y Urteaga, 1990).

No en vano, cabe citar a este respecto las deficiencias detectadas en materia cartográfica tras la invasión napoleónica, pues el ejército ocupante no tardó en descubrir que los archivos estaban repletos de

1 Con anterioridad el mismo Marqués de la Ensenada encargó en 1739 a los jesuitas Carlos Martínez y Claudio de la Vega un mapa general de España, quienes en 1743 presentaron 36 hojas que cubrían prácticamente el territorio nacional (Vázquez, 1982a; Capel, 1982). 
ilustraciones inservibles o de una cartografía trasnochada y llena de inexactitudes (Paladini, 1991; Castañón y Puyo, 2008; Torres y Naranjo, 2012).

En 1840, en un decreto de la Regencia Provisional fechado el 23 de noviembre, se seguían lamentando las carencias cartográficas del país. Se decía en sus prolegómenos que a la fecha sólo se contaba con los mapas realizados por Tomás López, "llenos de errores crasísimos" y referidos a una división territorial que ya no se correspondía con la vigente. Aun así, generalmente todo quedaba en lamentaciones y falta de concreción, o, en todo caso, en el desarrollo de iniciativas particulares como la abordada por el ingeniero militar Francisco Coello de Portugal y Quesada (Paladini, 1991).

Una sucesión de normas, directrices, instituciones y alguna que otra desavenencia, se ordenan cronológicamente y sin demasiado éxito a mediados del siglo XIX. Finalmente, por Decreto de 12 de septiembre de 1870 (Gaceta de Madrid nº 257, de 14 de septiembre), se crea el Instituto Geográfico (IG), que se habría de hacer cargo de todos los trabajos para el levantamiento del Mapa de España, recopilando lo poco o mucho hecho hasta la fecha por la Comisión del Mapa previa. El fin último será que sus labores desemboquen en la edición de la primera cartografía básica y homogénea del territorio nacional.

Aunque no pretendemos explorar la trayectoria de la construcción cartográfica del territorio español, ni los entresijos que explican el azaroso comienzo de su primera serie topográfica, sí creemos necesario (pues en parte ha de concretar el objetivo de nuestra propuesta) esbozar algunos de los factores, técnicos o de otra índole, que explican la persistencia de esas carencias cartográficas o la dilación en el tiempo de la ejecución de esa primera colección cartográfica nacional. En síntesis, los factores explicativos de esa dilatada trayectoria, la pluralidad de hechos y circunstancias que justifican tan compleja e intermitente labor cartográfica fueron:

- Existencia de unos precedentes carto-estadísticos territorialmente parciales y sin uniformidad metodológica (Paladini, 1991).

- Carencias metodológicas, técnicas y falta de información geográfica precisa, cuando no la pervivencia aún de interpretaciones repletas de convicciones acientíficas.

- Diversidad, coexistencia y uso ancestral de desiguales unidades de medida según territorios (Nadal y Urteaga, 1990). Se carecía todavía de un único sistema de medir que favoreciera una política de estandarización (Sena, 1979), necesaria, sobre todo, cuando había que afrontar proyectos sometidos a una creciente internacionalización (Puente, 1982; Cuadrado y Peset, 1997) ${ }^{2}$.

- Falta de formación, existencia de tensiones corporativas y celos profesionales entre diferentes colectivos y agentes responsables.

- Convivencia de posturas políticas y administrativas divergentes en relación con el desarrollo de las labores cartográficas, estadísticas y catastrales (Nadal y Urteaga, 1990).

- La sucesión de conflictos bélicos e inestabilidad política e institucional. Es cierto que generalmente los conflictos bélicos han representado avances en materia geográfica y cartográfica (Lacoste, 1977), pero no es menos cierto que la sucesión de conflictos en la España del XVIII y XIX no favoreció la paz social y política que requería el proyecto.

- Dificultades financieras, siempre presentes, que no pudieron hacer frente a las necesidades económicas de un proyecto de tal envergadura, y con tan importantes exigencias técnicas y profesionales.

- Oposición socioeconómica de ciertos colectivos y personalidades de la oligarquía tradicional. La vinculación entre las labores catastro-fiscales y la cartografía general, llegó a representar un escollo importante. La conjunción de ambas labores significaría un gran avance en el conocimiento de la riqueza y el patrimonio, aminorando la ocultación de la riqueza inmueble estadísticamente comprobada (Nadal y Urteaga, 1990).

Estos factores, entre otros, serán los ingredientes principales de las azarosas vicisitudes de la compleja y prolongada construcción del primer mapa topográfico nacional. Un proyecto siempre anhelado, pero que sólo se pudo abordar tras la creación del Instituto Geográfico en 1870.

2 La primera norma que apuesta decididamente por la instauración del Sistema Métrico Decimal (SMD) fue la dictada el 19 de julio de 1849 por Isabel II, bajo de la denominación de Ley de Pesas y medidas de 19 de julio de 1849, acompañada por un reglamento específico y el establecimiento de un programa de implantación y la previsión de un sistema de equivalencias entre las unidades tradicionales y el nuevo sistema. Sin embargo, la verdadera instauración del SMD sería repetidamente aplazada y contaría con no pocas reticencias y dificultades de toda índole (Puente, 1982). 


\section{EL MAPA TOPOGRÁFICO NACIONAL Y SUS HERRAMIENTAS}

Las pesquisas y labores previas a la edición del Mapa Topográfico, claves para comprender el presente (Moral, Pro y Suárez, 2007), comenzaron casi inmediatamente y bajo la dirección de Carlos Ibáñez e Ibáñez de Ibero.

En su plan general (septiembre de 1870) se establecía el proyecto de levantar el Mapa Topográfico de España a escala 1:50.000, aplicando a la par el tan traído y llevado SMD. La cuestión del número de hojas aún no se había concretado, pues se desconocían las coordenadas precisas de diversos puntos del contorno nacional.

Se adoptó también, la necesidad de establecer una norma avanzada para la representación del relieve y la altitud, eligiendo para ello el sistema de "curvas de nivel" en sustitución del sistema de "normales". También se hacía necesaria, y así se recogía en los trabajos cartográficos, la expresión planimétrica y el examen de los deslindes municipales, una información de la que no se disponía y que, entre otras consecuencias, habría de acentuar aún más el grave problema de la ocultación de los bienes patrimoniales que representaba el registro municipal de los Amillaramientos (García-Badell, 1942; Pro, 1989, 1992 y 1995; Feo, 2002; Alcázar y Chica, 2011; y otros). Del mismo modo se había de indicar las grandes masas de cultivo y cuantos aspectos planimétricos y altimétricos fueran requeridos por la dirección.

El desarrollo del Mapa Topográfico Nacional, gracias al impulso de su primer responsable y al esfuerzo de un notable equipo de topógrafos, pronto vería sus primeros resultados. En 1875 se editaba la primera hoja de la serie (Vázquez, 1982b); y en 1968 se concluía con la impresión de la hoja nº 1.125 de San Nicolás de Tolentino (Las Palmas) (Paladini, 1991; Urteaga y Nadal, 2001).

Una de las principales herramientas, aunque no la única, que coadyuvaron al desarrollo de la nueva cartografía topográfica fueron las conocidas como "minutas"; cartografía de campo manuscrita a escala 1:25.000 que, dada su calidad y detalle, será la principal fuente informativa de nuestros venideros argumentos.

Se contaba con un personal técnico preparado, con una serie de labores de inspección planimétrica y topográfica, así como con la confección de las citadas "minutas" o "planillas" que, a modo de apuntes, compendiaban las tareas previas a la edición del topográfico definitivo, donde se habría de sintetizar esa información de campo.

Tales "minutas" constituyen en ocasiones las primeras representaciones cartográficas de ciertos territorios nacionales, una rica colección que incluye "minutas planimétricas", "minutas altimétricas" y "minutas conjuntas", realizadas principalmente entre 1870 y 1950. Son mapas manuscritos realizados mediante el desarrollo de ciertos "itinerarios con brújula" y que conjugan la información cartográfica preexistente, adaptada a las nuevas técnicas, y su actualización mediante la inspección directa del terreno, distanciándose de las tradicionales "labores de gabinete". Tales "minutas" expresan principalmente los trabajos de triangulación, medida de distancias, altitudes, masas de cultivos, vías de comunicación, construcciones y expresión de accidentes naturales y/o humanos.

Los núcleos de población, necesitados de una dimensión escalar más definida (generalmente 1:1.000, 1:2.000 ó 1:5.000) sólo aparecían esbozados en las "minutas", pues para estos importantes parajes se levantaron los denominados "planos de poblaciones", mapas también manuscritos de cascos urbanos realizados entre 1870 y 1950 y previos a la realización del Mapa Topográfico Nacional.

En tercer lugar, dado el desconocimiento cartográfico que se poseía de los contornos municipales, hemos también de mencionar la importante información geográfica que brinda la consulta de las conocidas como "actas" y "cuadernos de líneas límite", documentos de reconocimiento directo que facilitaron los deslindes municipales y el registro de una rica red de mojones de término y estaciones de observación.

Esta interesante documentación cartográfica y textual, archivada durante décadas en los fondos del IGN, es en la actualidad, y tras su digitalización, una fuente accesible "on-line" mediante la consulta del portal del "Centro de Descargas" del Centro Nacional de Información Geográfica (IGN)3.

\section{LA PROVINCIA DE CÓRDOBA EN EL MAPA TOPOGRÁFICO NACIONAL}

Con el fin de comprobar el papel que el hábitat rural jugó en la construcción de la primera edición del Mapa Topográfico Nacional, hemos elegido como ejemplo ilustrativo los trabajos de deslinde y cartográfi-

3 Ver http://centrodedescargas.cnig.es/CentroDescargas/catalogo.do\#selectedSerie. 
cos realizados en la provincia de Córdoba en las últimas décadas del siglo XIX y recogidos en los aludidos documentos, que habrían de servir para la posterior edición del Mapa Topográfico.

\subsection{El territorio y sus singularidades}

El conjunto de la provincia, cuyos límites quedaron prácticamente definidos tras la remodelación administrativa de 1833, habría de quedar recogida en un total de 41 hojas del Mapa Topográfico Nacional 1:50.000 (Figura 1). La mayoría de sus hojas, en su primera edición, se publicaron en la última década del siglo XIX, siendo las más antiguas las que se localizaban en el norte y centro de la provincia; y las más modernas, ya entrado el siglo XX y con alguna excepción, en la mitad sur provincial o en los contornos de las provincias vecinas. Así, la horquilla cronológica que comprende la publicación de la primera edición del Topográfico para la provincia de Córdoba está definida por los extremos temporales de 1890 y 1938.

Las razones que justifican la elección de la provincia de Córdoba para el presente estudio son muy variadas. Una de las más significativas es el temprano comienzo de las labores cartográficas para la mayoría de los términos municipales de Córdoba pues, aunque la edición de sus hojas se retrasó a la década de los noventa del siglo XIX, los "cuadernos de líneas límite" o las "minutas" de los municipios cordobeses se confeccionaron en sus primeras versiones entre 1871 y 1872 . Lo cierto es que a partir de 1870 los trabajos topográficos se trasladaron a Andalucía (provincias de Córdoba, Sevilla y Cádiz), y desde allí fueron avanzando lentamente de sur a norte (Urteaga y Capdevila, 2013). Esta temprana elaboración de las "minutas" de un buen número de términos municipales cordobeses precisa el carácter pionero de las brigadas encargadas de levantar los primeros bosquejos cartográficos municipales; un carácter que, ante las carencias geodésicas y planimétricas detectadas por los operarios, condicionó que los técnicos se vieran obligados a tomar decisiones que resolvieran tales insuficiencias, lo que habría de influir en el proceder técnico de otras regiones y provincias.

Figura 1. Distribución aproximada y año de la $1^{a}$ edición de las hojas del Mapa Topográfico Nacional del IGN en la provincia de Córdoba.

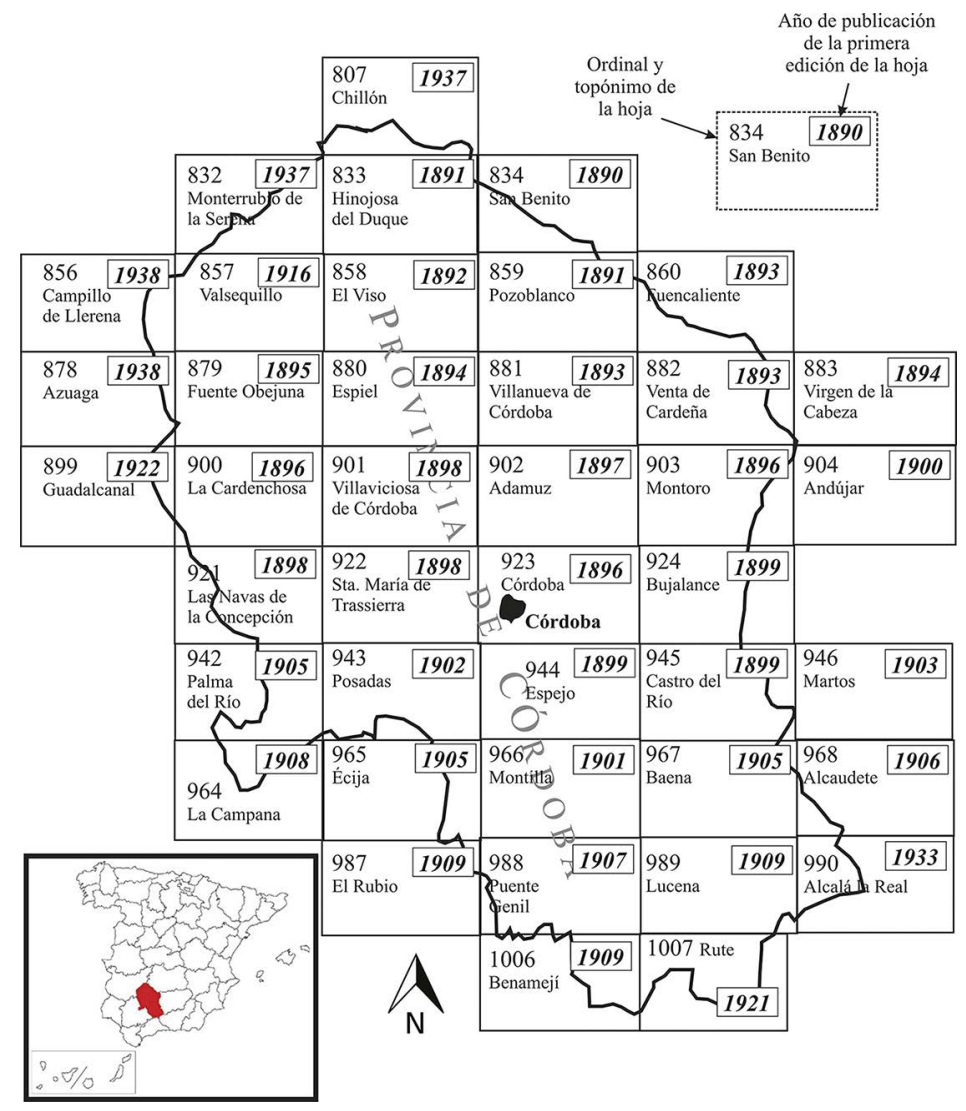

Fuente: López, García, Reyes y Rivera, (1989). Elaboración propia. 
El segundo de los aspectos a considerar es la pervivencia, en el último tercio del siglo XIX, de unas amplias comarcas caracterizadas por una antigua y todavía intensa vocación rural. La práctica totalidad de los municipios que integraban la provincia, con muy locales excepciones, mantenían un modo de vida y un paisaje marcados por la ruralidad, y sus paisajes agrícolas o pastoriles ("ager" y "saltus") se hallaban salpicados de un sinfín de viviendas, cortijos, haciendas, molinos, almazaras, lagares, chozos, etc. Una red de asentamientos rurales que aún integraban el verdadero tejido productivo de la provincia y constituían buena parte del entramado poblacional y demográfico de sus habitantes; siendo, al unísono, núcleos de producción, espacios residenciales, hitos visuales del paisaje, referentes toponímicos de parajes, escenarios sociales, patrimonio arquitectónico vernáculo, etc.

Y lo referido en el párrafo anterior se hallaba enmarcado por una geografía física contrastada (Sierra Morena, Depresión del Guadalquivir, Sierras Subbéticas y sus subdivisiones); lo que, por una parte, suponía la existencia de una pluralidad de paisajes naturales y humanos, distintos tipos de hábitats rurales y expresiones paisajísticas; y, por otra, representaba un excelente reto cartográfico, por sus variadas condiciones físicas y antrópicas, para las brigadas encargadas de levantar las primeras "minutas" del Topográfico Nacional.

Otra singularidad provincial que no podemos soslayar era la que se derivaba de su propia realidad municipal. Es conocido que a lo largo de los siglos XVIII y XIX la definición del mapa municipal español, a pesar de siglos de ordenación territorial, aún presentaba bastantes vacíos y no pocos desajustes. En 1842 la situación para Córdoba, con una población total censada de 306.760 habitantes, se describía con la presencia de un total de 70 municipios (Orduña, 2003), situación que se iría ajustando en censos posteriores hasta estabilizarse en 1897 con 74 términos municipales ${ }^{4}$.

Finalmente, teniendo presente lo expuesto al respecto de las reticencias socioeconómicas de ciertos colectivos ante el control fiscal que habría de ocasionar las mediciones topográficas y sus aplicaciones catastrales, la provincia de Córdoba había alcanzado cierta preeminencia, y de ahí su oportunidad en el presente análisis, en esas actitudes contrarias a tales pesquisas. La ocultación de información era una práctica habitual (Muñoz y Mata, 1999) y, en la provincia, pero con no poca influencia nacional, radicaban algunos de los personajes que más influyeron en el retraso de las investigaciones catastrales (Almansa, 1997 y 2008).

Pero el análisis de los 74 municipios que integraban la provincia en el último tercio del XIX sobrepasa los propósitos de este artículo. Por ello centraremos nuestro examen en una selección municipal que, por otra parte, consideramos representativa de los diferentes contextos físicos, históricos y paisajísticos de la provincia, ya que al desentrañar la información que de ellos nos proporcionan las fuentes previas a la edición del Mapa Topográfico, nos ofrecen una veraz y extrapolable muestra del significado que el poblamiento rural de las diferentes comarcas cordobesas adquirió a la hora de establecer las mediciones y otros datos necesarios para la confección de los primeros mapas topográficos. Por ello los términos municipales seleccionados y representativos son los seis que se expresan en la Figura 2. A saber: La Carlota, Conquista, Fernán Núñez, Palma del Río, Valsequillo y Zuheros.

\subsection{Las fuentes documentales}

En lo que se refiere a las "minutas" cartográficas para los municipios señalados, hemos estudiado la planimetría de 48 mapas manuscritos a escala 1:25.000. De ellos 36 corresponden a estudios planimétricos y 12 a pesquisas altimétricas. A estas "minutas", aunque no se conservan en el IGN la totalidad de las labores realizadas al respecto, se ha sumado el estudio de 15 "planos de población", en los que se muestran algunos de los núcleos demográficos de los términos elegidos, a escalas 1:2.000 ó 1:5.000, y que recogen una abundante información planimétrica y toponímica, suficiente para reconstruir un bosquejo muy certero de esos núcleos rurales y urbanos a finales del XIX (Tabla 1). A las fuentes citadas se ha sumado la inestimable información registrada en los "cuadernos" y "actas de líneas límite", pues en estos documentos se ponen las bases territoriales de las diferentes unidades municipales que habrían de levantarse en la cartografía nacional (Tabla 1).

\footnotetext{
4 Los 74 municipios citados son uno menos que en el momento actual, ya que en 1930 se sumará el término municipal de Cardeña, antigua "Venta de Cardeña" y aldea del término de Montoro.
} 
La cronología de este significativo material de archivo abarca, con algunas excepciones, un período comprendido entre 1871 y 1895. Las "minutas" más antiguas, realizadas entre 1871 y 1872, son las de carácter planimétrico, que se confeccionaban simultáneamente a los "cuadernos" y "actas de líneas límite". Una vez elaboradas las "minutas" le siguieron las "minutas altimétricas", que generalmente se trazaron en la última década del XIX; acompañadas, aunque también con alguna excepción, por el levantamiento de los citados "planos de población" (Tabla 1).

Figura 2. Situación de los términos municipales seleccionados para la provincia de Córdoba.

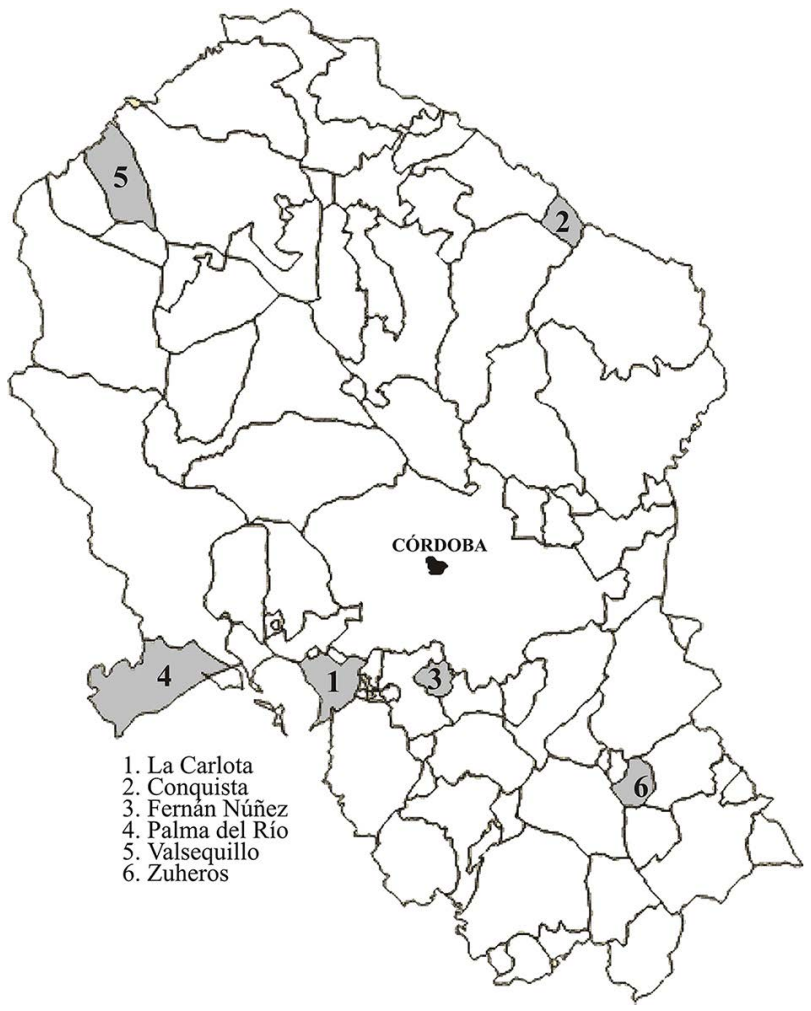

Elaboración propia.

Tabla 1. Relación del número de documentos previos al Mapa Topográfico Nacional analizados para los municipios seleccionados de la provincia de Córdoba.

\begin{tabular}{|l|c|c|c|}
\hline \multicolumn{1}{|c|}{$\begin{array}{c}\text { Municipios } \\
\text { (Comarcas) }\end{array}$} & $\begin{array}{c}\text { "Cuadernos } \\
\text { de Líneas Límite" }\left(\mathbf{n}^{\circ}\right)\end{array}$ & $\begin{array}{c}\text { "Minutas Planimétricas } \\
\text { y Altimétricas" }\left(\mathbf{n}^{\circ}\right)\end{array}$ & $\begin{array}{c}\text { "Planos de } \\
\text { Población" }\left(\mathbf{n}^{\circ}\right)\end{array}$ \\
\hline $\begin{array}{l}\text { Carlota, La } \\
\text { (Poblaciones Carolinas) }\end{array}$ & 5 & 7 & 8 \\
\hline $\begin{array}{l}\text { Conquista } \\
\text { (Los Pedroches) }\end{array}$ & 3 & 5 & 2 \\
\hline $\begin{array}{l}\text { Fernán Núñez } \\
\text { (Campiña Baja) }\end{array}$ & 8 & 16 & 2 \\
\hline $\begin{array}{l}\text { Palma del Río } \\
\text { (Valle del Guadalquivir) }\end{array}$ & 7 & 12 & 1 \\
\hline $\begin{array}{l}\text { Valsequillo } \\
\text { (Alto Guadiato) }\end{array}$ & 8 & 4 & 1 \\
\hline $\begin{array}{l}\text { Zuheros } \\
\text { (Sierras Subbéticas) }\end{array}$ & 4 & 48 & 15 \\
\hline Totales & 35 & 4 & 15 \\
\hline
\end{tabular}

Fuente: Archivo Digital del Centro de Descargas del IGN, en http://centrodedescargas.cnig.es/CentroDescargas/. Elaboración propia. 
La lectura y examen de este material cartográfico representa virtudes innegables para la reconstrucción paisajística de la Córdoba y la España de finales del XIX y principios del XX, tanto por su factura como por la abundancia y detalle de la información que representan, así como por las garantías de exactitud que se derivan de las técnicas empleadas y de los controles administrativos a los que se sometía cada una de las "minutas" y restos de instrumentos (Moya, Cuesta y Sánchez, 2015).

Uno de los primeros hechos que avalan esas virtudes es el propio proceder de los topógrafos. Alejándose de principios cartográficos de "gabinete", los resultados cartográficos que plasman las "cartas de líneas límite", "minutas" y "planos de población" son la consecuencia del contacto directo con el territorio, pues representan las observaciones realizadas por los técnicos, así como los recursos que estos emplean para la medición de áreas, ángulos, distancias, alturas, etc. Constituyen, por tanto, una herramienta cartográfica en la que se registran los detalles, sugerencias y observaciones de los técnicos, sin obviar, cuando así lo requería el caso, apreciaciones personales o la alusión a dificultades técnicas que impedían o limitaban las labores encomendadas.

No suelen disfrutar de un acabado especialmente lucido o formalmente atractivo, pues, como es fácil de intuir por lo citado, son un material interno del IG en el que plasmar, después, la información que habría de ser utilizada en la posterior edición de la serie topográfica nacional de escala 1:50.000. Generalmente se conciben sobre hojas cuadriculadas en las que se registran los distintos "itinerarios con brújula" realizados por los topógrafos y las observaciones manuscritas que estos anotan. Se usa una escasa gama cromática para presentar la planimetría, el relieve o los accidentes naturales o humanos. El tinte negro es el común, seguido del azul para los elementos acuáticos (ríos, arroyos, fuentes, lagunas, etc.); y, en tercer lugar, destaca la presencia, aunque no siempre, de trazos o textos en tinta roja, que suelen reservarse para anotaciones o añadidos incluidos con posterioridad al levantamiento originario del plano 5 .

Cuentan con una riqueza toponímica extraordinaria, expresada siempre con una caligrafía manuscrita de gran calidad, con el fin de facilitar la lectura posterior de ese abundante bagaje informativo. Nombres que, por otra parte, se acompañan de códigos numéricos y alfabéticos que identifican, con sus correspondientes leyendas, vértices, accidentes naturales, fuentes de agua, mojones de lindes municipales o parcelas de masas de cultivo y cubierta vegetal.

Finalmente, reforzando el valor que este material cartográfico atesora, cada hoja era visada al menos cuatro veces. La primera firma la estampaba el topógrafo que había realizado la "minuta" o cualquiera de los otros documentos; la segunda correspondía al jefe de la brigada de trabajo al que pertenecía el topógrafo; la tercera justificaba la revisión y aprobación del jefe provincial; y, por último, todas las hojas y documentos contaban con la firma, aprobación y sello del director general del IG. Un proceso de inspección que, entre otras circunstancias, se hacía necesario para velar por la validez de las observaciones y los métodos topográficos utilizados, a la par que acreditaba la exactitud de cada documento.

El lector, con los prolegómenos expresados, ha de comprender el interés y la riqueza informativa que entraña el análisis de tan exhaustivas averiguaciones. Sin embargo, para el presente trabajo nos fijaremos sólo en uno de los aspectos que, quizás por su originalidad, más no ha llamado la atención de la lectura y examen de dichos fondos.

La inexistencia aún de las redes de triangulación menores o la debilidad de la todavía incipiente red de vértices geodésicos, propició que los topógrafos, ayudados de los "itinerarios con brújula" y la observación directa, tuvieran que resolver tales carencias acudiendo, como veremos, al establecimiento de redes de triangulación básicas y mediciones de referencia locales que pudieran ser posteriormente validadas con las redes geodésicas mayores. $\mathrm{Y}$, en un buen número de casos, sobre todo en las amplias extensiones rurales, fue el hábitat rural, caseríos, haciendas y cortijos, los que se utilizaron como referentes de tales prácticas y mediciones. Esto lo comprobaremos, a título de ejemplo, en los "cuadernos de líneas límite" y en las "cartillas" o "minutas" confeccionadas para los términos cordobeses elegidos, si bien será una práctica común para el conjunto del territorio nacional.

5 En ocasiones el tiempo que trascurría entre la realización de la "minuta" y la edición definitiva de la hoja del Mapa Topográfico Nacional provocaba que ciertos aspectos o elementos reflejados en las "minutas" debieran perfilarse o modificarse para adecuarlas o actualizarlas a la fecha en la que se iba a proceder a la edición final. Ello solía traducirse en añadidos o anotaciones en color rojo sobre las cuartillas originales. 


\subsection{Labores topográficas y hábitat rural en La Carlota}

Antigua fundación ilustrada del siglo XVIII, bajo los auspicios de Carlos III y el diseño de Pablo de Olavide, había sido la capital de las colonias occidentales de Andalucía, que integraban los asientos de San Sebastián de los Ballesteros (Córdoba), Fuente Palmera (Córdoba) y La Luisiana (Sevilla). Su término, siguiendo los principios de inspiración francesa e ilustrada, se organizó mediante el diseño de un núcleo urbano compacto (La Carlota); varios "departamentos", organizados alrededor de sus respectivas aldeas; y un buen número de viviendas dispersas unidas a los cultivos y al trazado de las vías de comunicación ${ }^{6}$. En este último aspecto hay que resaltar que buena parte de los objetivos del proyecto carolino estuvieron directamente relacionados con la protección y repoblación del Camino Real por el puerto de Despeñaperros y las campiñas andaluzas, lo que explica el importante significado articulador que posee esa antigua vía, cuyo recorrido actual, con algunos cambios, coincide con la A-4.

Las labores topográficas se iniciaron con la confección de los "cuadernos de líneas límite", pues había que testar con la mayor exactitud posible los contornos del término municipal. Estos documentos se crearon a lo largo de 1871.

Sería muy prolijo presentar un examen minucioso de las observaciones recogidas en los "cuadernos de líneas límite", pues se realizaron tantos cuadernos como municipios limítrofes posee el término de La Carlota. El análisis del Cuaderno que describe los límites y mojones terminiegos de La Carlota con el municipio de Santaella habrá de ser suficiente para concretar el papel que se le asigna al hábitat rural, especialmente el disperso, en esta importante labor, pues generalmente molinos, caseríos o casas de labor aparecen referenciados topológicamente para observar y situar uno o varios mojones de la línea límite ${ }^{7}$. En dicho trayecto o "itinerario" el topógrafo reseña un total de 63 puntos o "estaciones" de observación, trazando visuales y sus rumbos correspondientes hacia diferentes elementos y, en ocasiones, proporcionando la distancia respecto a dichos elementos.

Así mismo, junto al caserío diseminado, los topógrafos también señalan la utilidad cartográfica de ciertos elementos y construcciones del poblamiento concentrado como las torres parroquiales de La Carlota o Aldea Quintana, así como elementos infraestructurales como las antiguas torres de comunicación. Todo ello especialmente destacado en el relieve horizontal del "glacis villafranquiense" que constituye el sustrato físico de la colonización carolina. Para confirmar tal proceder, en los citados "cuadernos" se citan en repetidas ocasiones las observaciones de los hitos terminiegos respecto al Molino del Albercón, el Caserío de Zafra, el Molino del Escarramal, la Casilla de los Algarbes, Casa de las Monjas, la Casa de Manuel Escribano, Casa de Antonio Leiva, la Casilla del Tejar, la Casa de Miguel Otero, la Casa del Jurado o el Molino de los Algarbes.

Sin que podamos exponer aquí la totalidad de las mediciones y referencias de los restantes "cuadernos" del deslinde de La Carlota con sus vecinos terminiegos, pero evidenciando en ellos que este mismo proceder se sigue en todos, es el momento de acudir a la expresión cartográfica del municipio de La Carlota en las "minutas planimétricas" de 1871 y 1872.

Las tres "minutas" de 1871, realizadas por el topógrafo Juan García, dividen el término de La Carlota en tres zonas o porciones. Traslada a ellas todas las estaciones de observación de las líneas límite respecto a los municipios circundantes, y señala, siguiendo las indicaciones de los "cuadernos" de deslinde y sus propias mediciones, las relaciones visuales y distancias respecto a hitos significativos del territorio. En ocasiones tales hitos son oteros destacados en el horizonte, que se señalan por su utilidad como vértices; y en un buen número de ocasiones la referencia empleada será la presencia de una vivienda rural diseminada, ya sea casa, chozo, molino, cortijo, etc.

Esas tres primeras "minutas", base del examen de campo, se integran en dos nuevas versiones o "minutas" globales que representarán, también a escala 1:25.000, la totalidad del término. Ambas se confeccionan en 1872. Con el fin de sinterizar nuestra exposición, pues la información es muy prolija, analicemos sólo la "minuta" de síntesis correspondiente al 6 de agosto de 1872.

Efectivamente, como cabía esperar y confirmando nuestra hipótesis de trabajo, la referida "minuta" señala la presencia de numerosas mediciones topográficas entre elementos planimétricos situados en el término. Y, en muchos de los casos, esas relaciones, especialmente de mojones terminiegos y estaciones de

6 El término municipal de La Carlota cuenta, según el IGN y para 2015, con una superficie de $79 \mathrm{~km}^{2}$.

7 El "Cuaderno" aludido fue realizado por el topógrafo Jesús Robledo en julio de 1871. 
observación de las líneas límites, se establecen con viviendas rurales diseminadas próximas y observables desde la estación correspondiente, o inmediatas a elementos longitudinales como caminos o cursos fluviales.

Los topógrafos triangulan sus mediciones respecto a núcleos de población compactos como La Carlota, Aldea Quintana, Las Pinedas, Carlota Chica, La Victoria o San Sebastián de los Ballesteros. Generalmente suelen establecerse visuales y distancias relacionadas con campanarios de parroquias, torres y veletas de los ayuntamientos de esas poblaciones nucleares. Pero cuando no se dispone de visibilidad respecto a esos núcleos principales, los peritos no dudan en recurrir a torres de telégrafos, cercas o lindes de parcelas cultivadas, y, por supuesto, casas, casillas, chozas, tejares, lagares, molinos, cortijos y otras construcciones diseminadas por el municipio (Figura 3). Los cartógrafos encontraron en el municipio de La Carlota un territorio extraordinariamente dotado de un poblamiento rural nuclear y disperso sobre el que apoyar sus mediciones; circunstancia que era el resultado de la colonización demográfica llevada a cabo en el siglo XVIII y que, a finales del XIX, aún atesoraba buena parte de esa red poblacional dispersa estrechamente unida a la producción agraria de los terrazgos o a su cercanía a las vías de comunicación.

Figura 3. Esquema del término de La Carlota y del hábitat empleado como referencia planimétrica y geodésica en la "minuta" de su término, fechada el 6 de agosto 1872. Con texto rojo se expresa el poblamiento de referencia utilizado. Con líneas rojas discontinuas se indican las principales mediciones y rumbos trazados. Escala original 1:25.000.

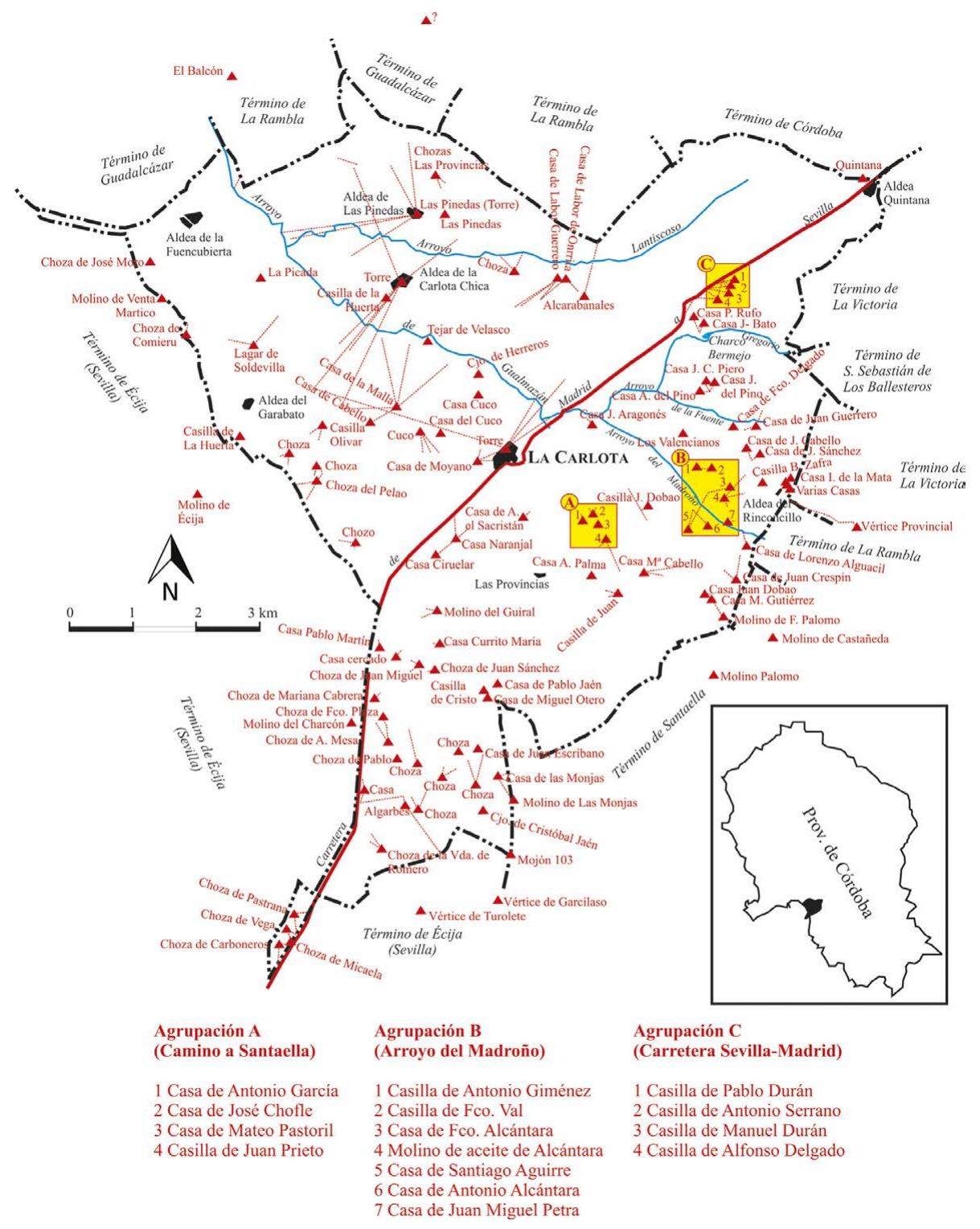

Fuente: Centro de Descargas del Archivo del IGN. Elaboración propia. 


\subsection{Hábitat rural y "Minutas" en el término de Conquista}

Al noreste de la provincia de Córdoba, en la unidad natural de Sierra Morena y en la comarca de Los Pedroches, se sitúa el municipio de Conquista, emplazado justo en el límite con la provincia manchega de Ciudad Real. Aunque en la actualidad su término está inscrito en la mancomunidad de Los Pedroches Conquista no se sumó nunca a las conocidas Siete Villas de Los Pedroches. La localidad se origina a lo largo de la Baja Edad Media, posiblemente a raíz de la existencia en el paraje de unas ventas junto al antiguo "Camino de La Plata". En 1569, cuando había reunido la población de diversas ventas y casas rurales cercanas, Felipe II le otorga el título de "villa", concediéndole un término formado por tierras comunales de Las Siete Villas de los Pedroches.

Poco poblada desde la antigüedad, Conquista alcanzaría su esplendor urbano y demográfico a finales del siglo XIX y principios del XX, sobre todo a raíz del interés económico y demográfico que habrán de suscitar las explotaciones mineras y la llegada del ferrocarril al norte de la provincia. Ese efímero período de esplendor económico y minero coincide, en parte, con las labores topográficas del Instituto Geográfico, el deslinde de su municipio, sus "minutas" topográficas, etc.

Veamos cómo aparece representado el hábitat rural, ahora de carácter serrano y "mariánico", protagonizado por el "saltus" ganadero, en esas averiguaciones topográficas de su término municipal.

Figura 4. Término de Conquista y del hábitat empleado como referencia en su "minuta" topográfica (1871). En rojo: poblamiento de referencia. Escala original 1:25.000.

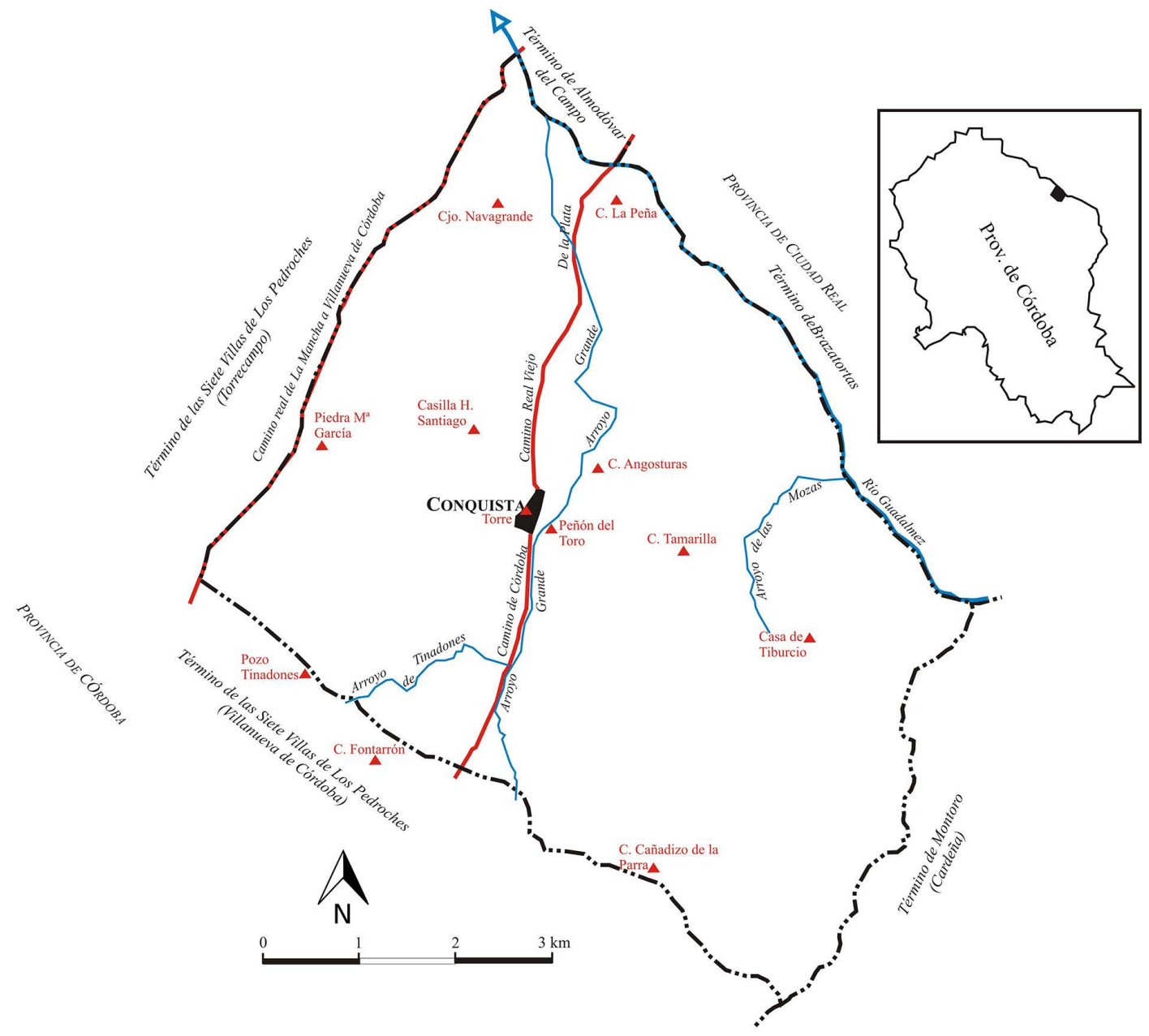

Fuente: Centro de Descargas del Archivo del IGN. Elaboración propia.

8 El término municipal de Conquista cuenta, según el IGN y para 2015, con una superficie de 38,6km². 
Entre 1871 y 1872 se realizan tres "cuadernos de líneas límite" con el objeto de definir los contactos de Conquista con sus vecinos. A estas pesquisas de deslinde se suma la realización de un total de tres "minutas planimétricas". Las "minutas" referidas muestran, en primer lugar, una densidad de cerros y enclaves topográficos muy aptos para el cálculo de mediciones, circunstancia que, sin duda, está asociada a las propias características montañosas que se suceden en su geografía.

Entre tales vértices se señalan el Cerro del Peñón del Toro, muy cercano a la localidad, el Cerro de las Angosturas, Cerro Tamarillas, Cerro de la Peña, la Piedra de María García o el Cerro del Cañadizo de la Parra ${ }^{9}$ (Figura 4). El mismo documento cartográfico muestra el valor visual de la torre parroquial de la localidad para levantar su topografía, así como la importancia de ciertas viviendas de labor dispersas por un término que, sin embargo, no disponía de la abundancia del poblamiento que sí caracterizaba al ejemplo referido de La Carlota, lo que, en cierto modo, habría de dificultar sustancialmente las labores topográficas del municipio pedrocheño.

Sin embargo, donde realmente vemos la importancia del poblamiento rural en la construcción de la cartografía de Conquista es examinando los "cuadernos de líneas límite". En estos documentos el topógrafo acude de manera recurrente a los cortijos ganaderos, casas de huertas y chozas dispersas por el término y especialmente próximas a los límites del término. Entre las construcciones rurales más destacadas podemos mencionar las siguientes: la casa de D. Baltasar, la casa de D. José Ramón, la casa de Da Isabel Cerro, la casa de Tiburcio, la casa-pajar de Juan Mata, la casilla de la Huerta de Santiago, el cortijo de Bartolomé de Castro, el pozo de Tinadones, el cortijo Torrubia, etc.

\subsection{Pesquisas topográficas en el término de Fernán Núñez}

En la Campiña Baja cordobesa, en un paisaje ondulado por la erosión y definido por las labores cerealísticas y olivareras, con profundas raíces señoriales, se halla el término de Fernán Núñez ${ }^{10}$. La bondad agraria de su tierras, sus caracteres climáticos mediterráneos y una prolongada presión humana, unido a su evolución geopolítica, han dispuesto un paisaje casi totalmente deforestado, intensamente agrarizado y marcado por la presencia de un poblamiento concentrado que articula, a su vez, un rico patrimonio de cortijos y caseríos diseminados (Naranjo, 1991 y 1995).

El levantamiento topográfico del término se sustentó en principio en el deslinde de su término. Para ello el Instituto Geográfico realizó un total de ocho "cuadernos de líneas límite". Los tres primeros en 1871, dos en 1893 y, finalmente, tres más "de nivelación" en 1894.

A los citados "cuadernos" de deslinde se sumó el levantamiento de cuatro "minutas": tres de tipo "planimétrico" y una cuarta de la modalidad "altimétrica". La más antigua data de 1871 y constituye la base fundamental del registro de campo realizado por el topógrafo José Cruz. A ésta le seguirán las "minutas" de síntesis posteriores, en las que se realizan ciertas anotaciones de interés para la edición definitiva de su hoja topográfica.

Si examinamos, primero, los "cuadernos de líneas límite" hemos de señalar una circunstancia relevante. Mientras en los términos precedentes hemos podido comprobar el importante valor otorgado al hábitat rural como elemento fundamental de la triangulación municipal de sus respectivos términos, en el de Fernán Núñez, especialmente escaso en cortijos y hábitat disperso, no se produce esta circunstancia.

Al contrario, dada la intervisibilidad de los núcleos de población campiñeses que rodean a Fernán Núñez, el topógrafo pudo prescindir en buena medida del poblamiento disperso como recurso topográfico, pues contaba con núcleos concentrados que facilitaban no sólo el trazado y levantamiento del término de Fernán Núñez, sino también buena parte de la Campiña Baja cordobesa. En este sentido cabe señalar el elevado significado que adquiere la torre de la parroquia de Fernán Núñez, pues se muestra como un verdadero vértice visual de prácticamente la totalidad del perímetro municipal. A esta circunstancia ha de sumarse también la presencia, sobre todo en los términos vecinos, de una colección de cerros susceptibles de usarse para la triangulación.

En respuesta a los hechos citados, la información registrada en los "cuadernos" y "minutas" otorga una menor consideración a la red de cortijos campiñeses que rodea al municipio de Fernán Núñez, con

9 Sin embargo en el momento actual el municipio sólo cuenta con un único vértice geodésico: el Cerro Chaire, con poco más de 648 msm. 10 El término municipal de Fernán Núñez cuenta, según el IGN y para 2015, con una extensión de 29,8km². 
la excepción de ciertas referencias a casas de labor, cortijos o molinos estratégicamente emplazados en las cercanías de algún elemento longitudinal relevante. La triangulación del municipio disponía de una red de núcleos concentrados próximos y visibles en el paisaje campiñés, pues generalmente todos ellos presentaban, como hoy, una localización elevada y fácilmente defendible. Localización que, unida a su propia estructura urbana, les confieren el carácter de "pueblos-fortaleza", condición de tanta importancia en la construcción territorial de la frontera bajomedieval castellano-nazarí (López, 1981 y 1994).

Si observamos la "minuta" originaria, de 1871 (Figura 5), es evidente, como lo es el examen de la relación de líneas límite, que la planimetría del término, tanto en sus componentes internos como perimetrales, se traza con cierta facilidad entre la torre-campanario de la parroquia de Sta. Marina, y numerosos enclaves situados en el exterior del municipio. Unas veces esos enclaves visuales son cerros, vértices topográficos incuestionables en el paisaje de la Campiña Baja. En otras ocasiones serán las torres y construcciones de los cascos urbanos vecinos.

El vértice septentrional adoptado fue el Cerro Gordo; a levante, el cerro del Frenil, en el vecino municipio de Montemayor; al sureste se señalaba el vértice del Castillo de Montemayor; en el cuadrante suroeste, en pleno municipio de La Rambla, se alzaba el cerro de La Montesina ${ }^{11}$; y, por último, a poniente, se localizaba el vértice y paraje de Las Zorreras (Figura 5).

Figura 5. Minuta del término de Fernán Núñez (1871) realizada por José Pastor (original 1:25.000). Nótense las líneas de triangulación respecto a vértices periféricos y el papel de la torre-campanario de la parroquia de Sta. Marina, así como

la importancia de ciertos puntos del arroyo Ventojil y otros lugares asociados a la presencia de caseríos y cortijos.

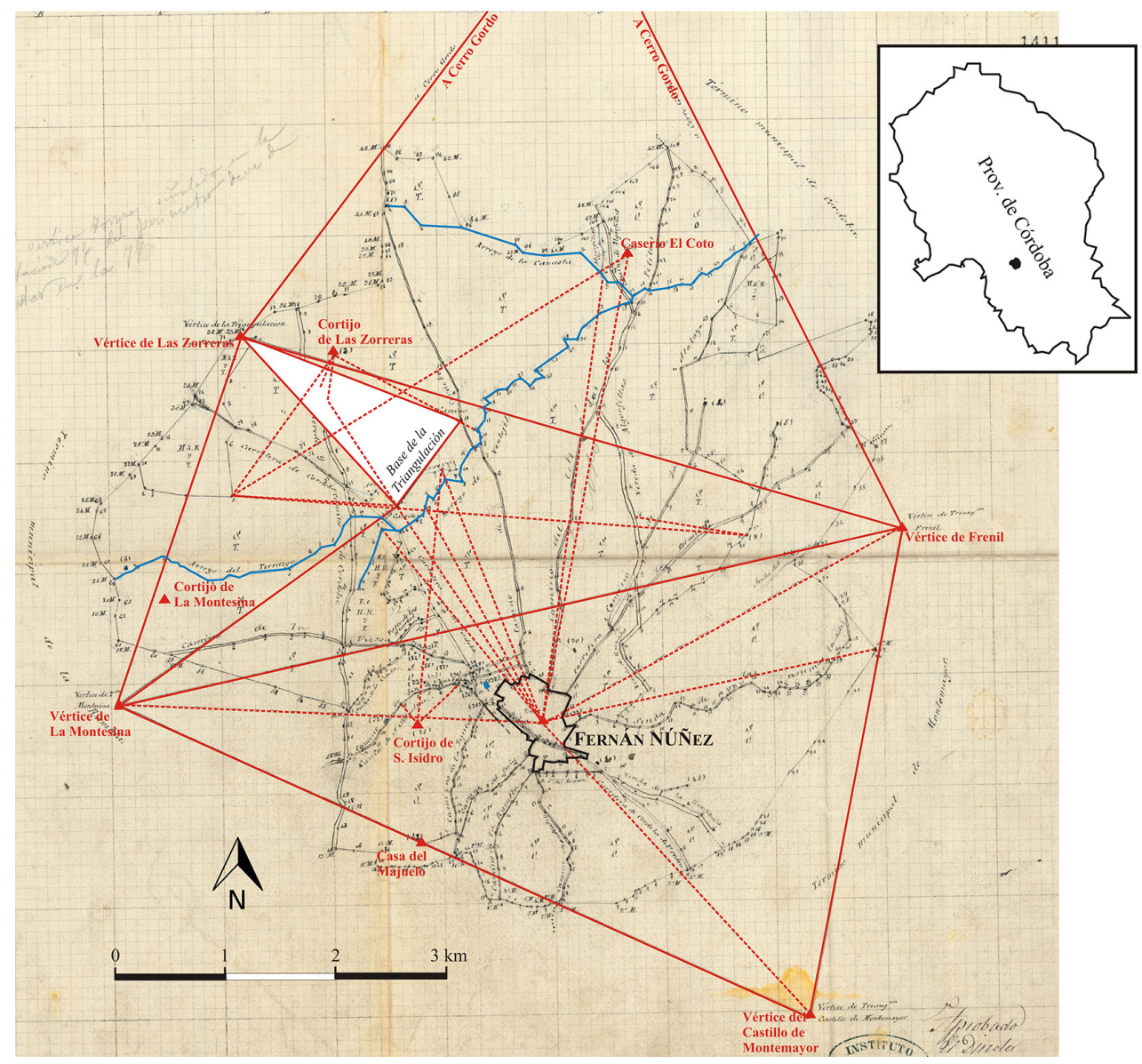

Fuente: Centro de Descargas del Archivo del IGN. Elaboración propia.

11 Hoy el Castillo de Montemayor sigue constituyendo un hito significativo de la red de vértices geodésicos de la provincia de Córdoba. El vértice físico se sitúa sobre la torre más alta del castillo, con una altitud sobre el nivel del mar de unos $413 \mathrm{~m}$. El vértice de La Montesina, en el término de La Rambla, se mantiene en la actualidad. Se sitúa en una pequeña loma, en terreno de labor y con una altitud sobre el nivel del mar de unos $348 \mathrm{~m}$. 
El topógrafo establece la geodesia del municipio dibujando un triángulo base desde el vértice de Las Zorreras, enclave que, por otra parte, constituía el mojón de término $n^{\circ} 33$ del perímetro municipal. Dicho triángulo se completaba con los vértices de su base, uno situado en el contacto entre dos masas de cultivo próximo al arroyo Ventojil, y el último en un punto expreso del antiguo Camino a Córdoba. La distancia entre ambos vértices constituía la base de la triangulación.

El hito altimétrico de Las Zorreras se relaciona con otros vértices situados fuera del municipio y éstos, a su vez, se conectan con el hito del campanario de la parroquia de Santa Marina. La disponibilidad de estos hitos y lugares de gran valor visual, como ya hemos citado, restará presencia en la triangulación a los asentamientos diseminados del municipio. Sin embargo, al ser una práctica común, el topógrafo no duda en incluir ejemplos de este hábitat diseminado con fines cartográficos. Para la definición del perímetro del municipio y sus mojones se alude a las distancias existentes respecto a un antiguo molino del viento, la Casa de Ponce o algunos cortijos. Así mismo, en el interior del propio término se establecen ejemplos o enclaves especialmente definidos por sus destacados emplazamientos: la casa de Ponce, la casa del Majuelo, el caserío del Coto, los cortijos Cuarto Carrillejo, Cuarto del Álamo, de La Montesina, el de Las Zorreras, el de San Isidro o Pilillas, sin olvidar incluso la mención de un antiguo "molino de viento" (Figura 5).

\subsection{Hábitat rural y topografía en Palma del Río}

En pleno Valle del Guadalquivir, formando parte de su Vega y a poniente de la provincia de Córdoba, se extiende el municipio de la localidad de Palma del Río ${ }^{12}$. Su superficie está comprendida entre las estribaciones de Sierra Morena, al norte; y la campiña de la "raña" o "glacis villafranquiense" de las Nuevas Poblaciones Carolinas (Naranjo, 2013), al sur; mientras a levante y poniente se extiende el corredor de la Vega y Terrazas del Guadalquivir en su confluencia con el curso del río Genil (Torres, 2013).

El examen de los "cuadernos de líneas límite", un total de siete, ya nos da indicios evidentes de la presencia y el uso de los caseríos rurales en el levantamiento topográfico del municipio. Casas rurales, molinos o cortijos, unidos a una incipiente red de vértices geodésicos como el "Cabezo", la Sierrezuela, San Cristóbal o las torres de núcleos urbanos, facilitaron la labor de inspección y levantamiento cartográfico. Entre los caseríos dispersos que más se repiten en los "cuadernos" del deslinde municipal cabe citar, por ejemplo, la casa-palacio de Moratalla, el Cortijo de la Parrilla, el Cortijo del Encinarejo, el Cortijo del Bramadero, la Casa de Escalonía, el Cortijo de Nublos, la Casa de los Canónigos, la Casa de las Caleras, la Casa de las Monjas, ciertos molinos aceiteros, etc.

Esa información y la importancia otorgada al poblamiento rural se hacen aún más patente en las "minutas" cartográficas, pues son muy numerosos los ejemplos del hábitat rural que se seleccionan para levantar la topografía del municipio (Figura 6); incluyendo entre tales asentamientos lugares emblemáticos como el santuario de Ntra. Sra. de Belén, la estación del ferrocarril Córdoba-Sevilla, la torre campanario de la parroquia de Ntra. Sra. de la Asunción, molinos aceiteros, la Torre de Peñaflor, chozos de agricultores, o las no menos representativas norias que se disponían en las márgenes del Genil (Torres Balbás, 1940; Córdoba de la Llave, Albendín, García, \& Ortiz, 2004).

En la Figura 6 podemos observar cómo el término de Palma del Río se levanta topográficamente gracias a la presencia, por una parte, de una serie de vértices; $y$, por otra, de una nutrida red de viviendas y la centralidad del campanario de la Asunción. Entre los vértices sobresalen los oteros de San Cristóbal ${ }^{13}$, la Serrezuela ${ }^{14}$, el Toril, el Cerro de la Cabeza ${ }^{15}$ o Longueras $^{16}$.

El núcleo principal de población albergaba el hito visual de la esbelta torre de la Asunción, que permitió la triangulación del perímetro de la villa o el cálculo de distancia respecto a caminos de su ruedo o a los cursos del Guadalquivir y Genil. Y en tercer lugar destacaba una rica muestra de casas y cortijos diseminados que facilitaban las mediciones respecto a caminos, lindes de cultivos, ferrocarril, líneas lí-

12 El término de Palma del Río, según el IGN y para 2015, cuenta con una extensión de 200,2 km².

13 Vértice actual del municipio palmeño conocido como San Cristóbal 3. Se sitúa a 128,88 m sobre el nivel del mar, sobre la cumbre del cerro homónimo y a sólo $10 \mathrm{~m}$ de las ruinas de la antigua ermita rural de San Cristóbal.

14 Vértice geodésico actual con una altitud sobre el nivel de mar de 158,141 m.

15 Este vértice se sitúa en la actualidad a una altitud de $152,543 \mathrm{~m}$ sobre el nivel del mar.

16 Este vértice creemos que se corresponde en la actualidad con el vértice conocido como "Mojón Gordo", emplazado a una altitud de 203,562 m entre los términos de Palma del Río y Hornachuelos, pues constituye en sí un mojón de la linde entre ambos municipios. 
mite o cursos fluviales. Entre estos hitos del hábitat rural disperso no sólo se da cabida a las tradicionales casas de labor, cortijos o casas de olivar, pues también se seleccionan el Santuario de Ntra. Sra. de Belén, la antigua estación ferroviaria y algunas de las norias que aún adornaban el cauce del río Genil.

Figura 6. Término de Palma del Río en 1871/72 según las "minutas" planimétricas de Agapito Martín de Castro, León Sánchez Molina y otros (1:25.000 en el original).

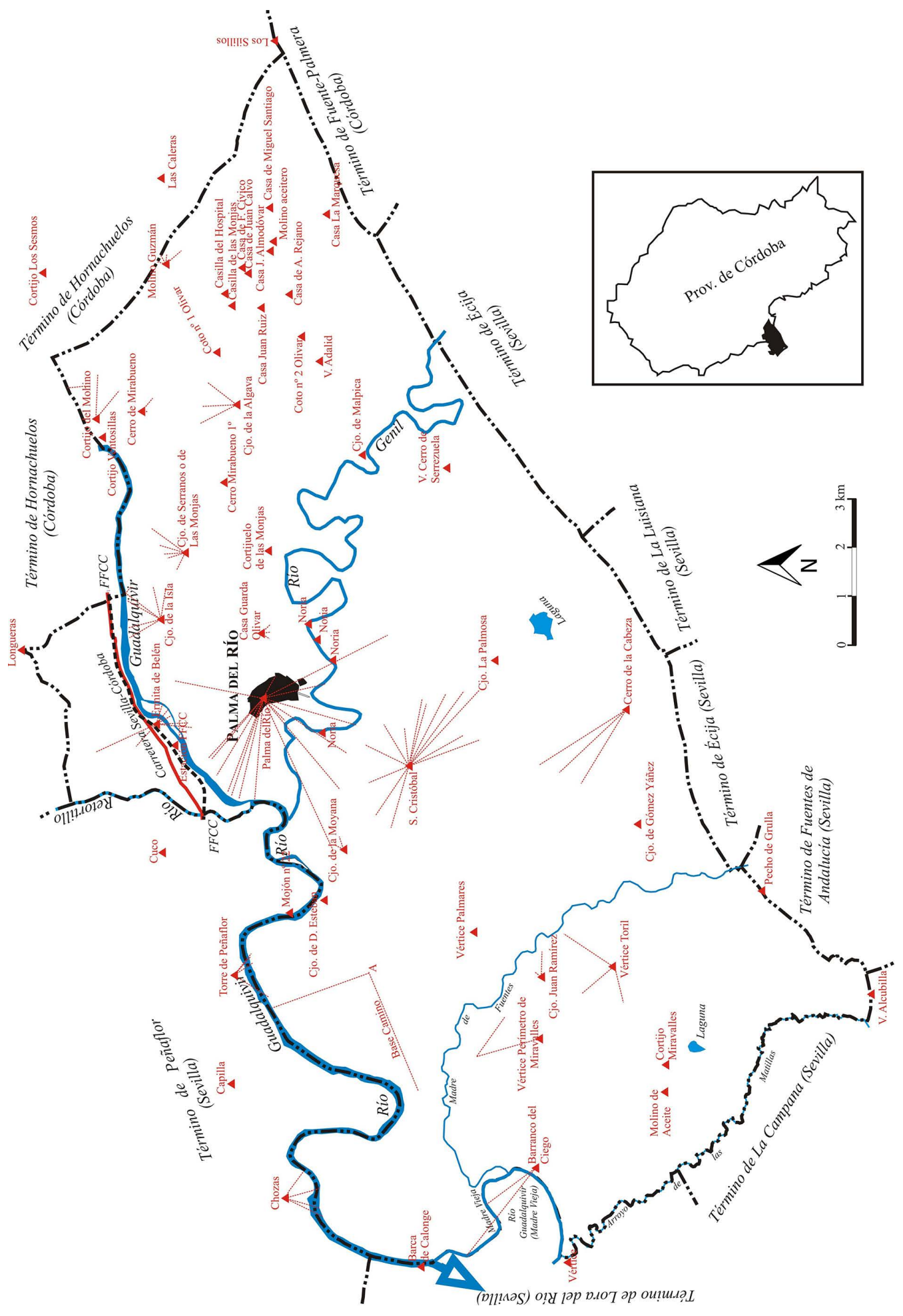

Fuente: Centro de Descargas del Archivo del IGN. Elaboración propia. 


\subsection{Hábitat rural y topografía en Valsequillo}

El municipio de Valsequillo, situado en la comarca septentrional serrana del río Guadiato, constituye en el momento actual una jurisdicción con cifras de población bajas y una densidad demográfica que no alcanza los $4 \mathrm{hab} / \mathrm{km}^{2}$. Posee una extensión de $121,8 \mathrm{~km}^{2}$ y un paisaje dominado por el secano cerealístico, el olivar, el pastizal y una laxa dehesa mediterránea, gozando en tiempos históricos de un ideal emplazamiento para el control de las comunicaciones.

Este municipio surgió originalmente, a propósito de esa localización estratégica, como una antigua venta que suministraba servicios a los viajeros entre el reino de Córdoba y Extremadura; para después, en la Edad Moderna, constituir una aldea dependiente de la villa de Fuente Obejuna (Córdoba), que por entonces era señorío de la orden de Calatrava y escenario histórico-literario de la conocida crónica que ensalzara Lope de Vega en el siglo XVII.

En el siglo XVI la aldea de Valsequillo funda su parroquia particular, pero no será hasta el siglo XIX cuando adquiera el rango de villa municipal como cabeza del término de las "Cinco Villas", pues a él se asociaban tal número de aldeas próximas. En esa misma centuria, en 1842, el municipio de las "Cinco Villas" se segrega en diferentes entidades territoriales, originando el actual municipio de Valsequillo de Córdoba. Su jurisdicción sufrió graves daños a lo largo de la Guerra Civil Española (Moreno, 1985; Pajuelo, 2008), lo que, entre otros perjuicios, supuso prácticamente la desaparición de su casco urbano y su posterior reconstrucción durante el Franquismo.

El estudio de los "cuadernos de líneas límite" y las "minutas" correspondientes, a pesar de sus particularidades naturales, económicas e históricas, arroja similar resultado a los términos ya comentados. El levantamiento del término se sustenta, primero, en la existencia y propuesta de varios vértices geodésicos, especialmente situados en cerros notorios. Entre tales vértices cabe citar la presencia tanto de enclaves fuera del término como dentro de él.

Fuera del municipio se marcan los vértices del Cerro Bonal ${ }^{17}$ y el Cerro del Castillo de Maldegüello ${ }^{18}$, situados en el término de Los Blázquez; y en el municipio de La Granjuela, al sur, se utilizó el vértice de la Sierra de la Noria ${ }^{19}$. En el seno del término de Valsequillo se señalan varios oteros prominentes. Entre ellos podemos citar el Cerro Torozo, La Morala, Retamala, el vértice de Los Valles, vértice de la Sierra de la Cinta, de Sierra Trapera o el vértice terminiego del Rincón de Valdecarros, límite con el municipio de Hinojosa del Duque (Córdoba) ${ }^{20}$ (Figura 7).

A esa triangulación general, se suma la relevancia del propio núcleo de Valsequillo. Más concretamente del campanario de su antigua parroquia de Ntra. Sra. de la Concepción. A partir de éste se estructura una red de vectores visuales con otros elementos longitudinales como cursos de agua, caminos, ferrocarril a Almorchón (Cabeza de Buey, Badajoz) o caseríos más o menos distantes. Y, para completar esta red local de puntos en los que concentrar las mediciones, el topógrafo encargado de la planimetría del municipio ${ }^{21}$, siguiendo una práctica común y recurrente en todos los casos analizados, acude a la configuración de una serie de "vértices" o puntos locales de observación y medición aprovechando diferentes construcciones del hábitat rural del municipio (Figura 7). Así, por ejemplo, se hace uso de construcciones asociadas al servicio ferroviario a Almorchón, caseríos como la casa de Josefa Molera, la casa de Cerrejoncillo, la casa del Cerro Mirón, o la casa de Los Valles; a las que se suman, incluso, construcciones efímeras como algunos chozos. El recurso de acudir a tales construcciones efímeras se debió posiblemente a la falta de otras edificaciones rurales más estables en un municipio de clara vocación ganadera y que desde siempre había contado con muy escasos efectivos demográficos y un débil poblamiento diseminado (Figura 7).

17 A poniente del Cerro Bonal se encuentra el que sí constituye actualmente un vértice enclavado en el término de Los Blázquez, conocido como del Cerro Coscojo, con más de $728 \mathrm{~m}$ sobre el nivel del mar.

18 Se conoce también como Cerro del Castillo de Los Blázquez. Se sitúa en un cerro prominente que se eleva hasta los 753,649 m sobre el nivel del mar. Alrededor del vértice aún se observan los restos de la antigua fortaleza medieval.

19 Éste constituye actualmente uno de los dos vértices geodésicos situados en el término de La Granjuela. Se sitúa sobre el cerro homónimo que destaca en la Sierra de la Noria, con una altitud de casi $717 \mathrm{~m}$.

20 De los vértices referidos sólo han permanecido en el municipio y en el sistema de triangulación actual español los citados de La Cinta y Sierra Trapera. El primero se sitúa en el cerro más prominente de la Sierra de La Cinta, sobre una roca conocida como Peña de la Cigüeña y con una altitud de algo más de $767 \mathrm{~m}$ sobre el nivel del mar. El vértice de La Trapera, en lo más alto de la sierra homónima, se sitúa a una altitud de poco más de $778 \mathrm{~m}$.

21 El levantamiento de las primeras "minutas" planimétricas del municipio de Valsequillo en 1871 le correspondió al topógrafo Francisco Ponce. 
Figura 7. "Minutas" planimétricas del término de Valsequillo (1871/72) (1:25.000 en el original).

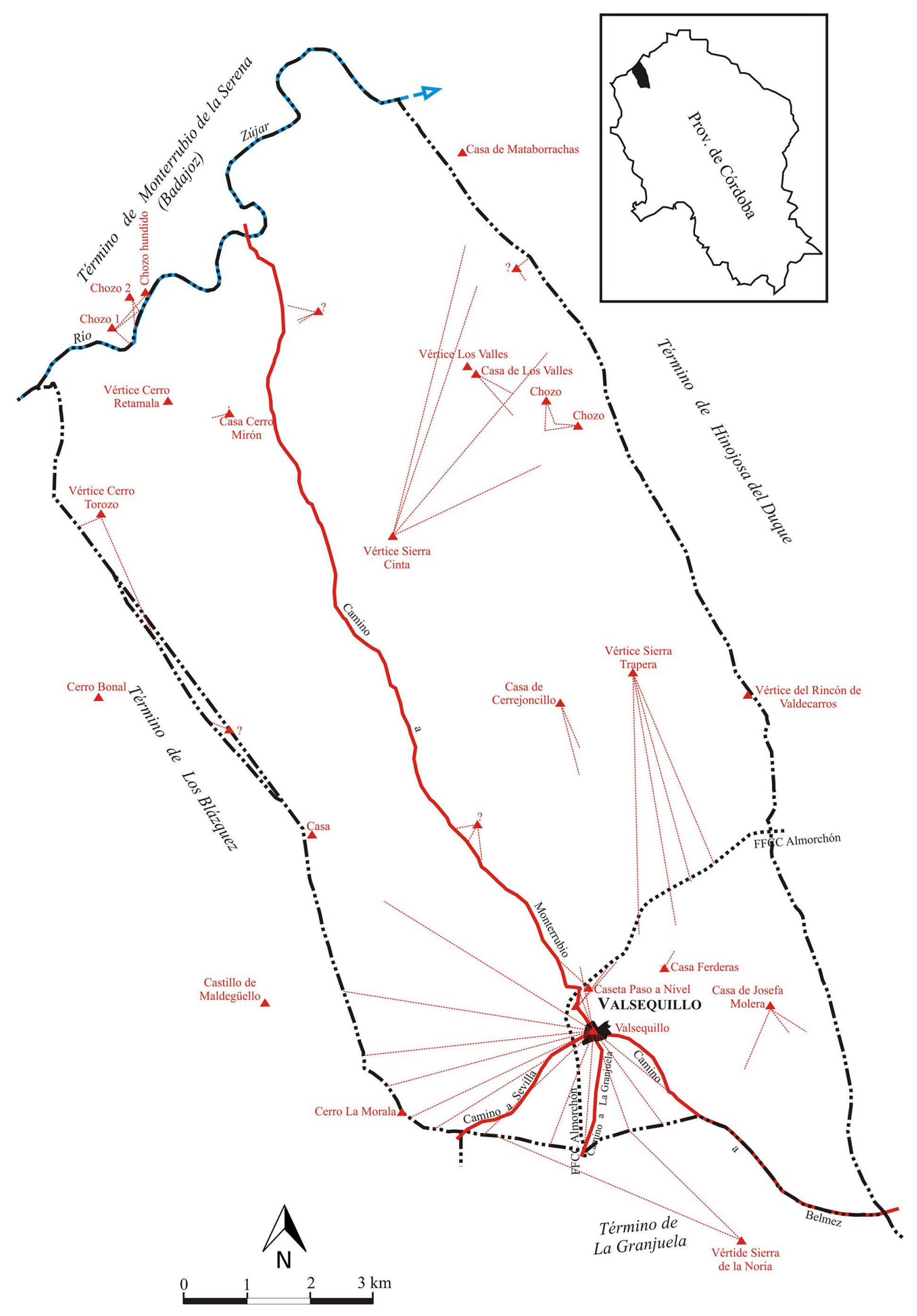

Fuente: Centro de Descargas del Archivo del IGN. Elaboración propia. 


\subsection{La construcción de la cartografía de Zuheros}

El municipio subbético de Zuheros, hoy una de las localidades cordobesas más valoradas turísticamente por sus paisajes y estampas pintorescas, presenta en la actualidad una extensión de $42,3 \mathrm{~km}^{2}$. Parte de su municipio se extiende por el actual parque natural de las Sierras Subbéticas, y cuenta con una historia señalada por el poblamiento defensivo y señorial que protegía la antigua frontera castellano-nazarí.

Buena prueba de ese papel defensivo se descubre al observar el embarazoso y particular emplazamiento de su caserío actual, y la aún más insospechada localización de su castillo. Un asiento demográfico que armoniza a la perfección con las intrincadas formas cársticas, el desfiladero del río Bailón, las laderas pobladas de olivar y las antiguas huertas y sembraduras de cereal, donde no es difícil tropezar con los despojos de antiguos cercados y viejas eras primorosamente empedradas.

En nuestro análisis hemos de señalar un hecho significativo. Al igual que ocurre en otros municipios montañosos, la presencia de elevaciones y cerros destacados favoreció la designación de vértices de triangulación de desigual importancia en el contexto territorial. Como ocurriera en los casos de Conquista o Valsequillo, Zuheros ya contaba en 1871 con una serie de hitos altimétricos que, sin duda, habrían de facilitar el trazado de vectores de observación y el cálculo de mediciones.

Si iniciamos nuestro examen por los "cuadernos de líneas límite", realizados por Casimiro Zubiría en 1871 o por Francisco Blasco Castro en 1943, vemos con facilidad cómo habitualmente los topógrafos trazan la planimetría del término acudiendo a la presencia de esos vértices de triangulación ya establecidos por los estudios llevados a cabo desde mediados del siglo XIX, siendo escasa la importancia inicial otorgada a puntos o estaciones con referencia en el hábitat concentrado o disperso.

En las relaciones de estaciones y mediciones de los tres "cuadernos" de 1871 prácticamente no se recogen citas al hábitat rural como apoyo cartográfico, siendo común, por el contrario, el recurso de identificar y situar vértices topográficos de cierta relevancia en el relieve subbético. Hecho que se justificaba aún más si tenemos presente que varios de esos vértices constituían marcas de la divisoria administrativa entre los términos municipales.

Así, por ejemplo, en el deslinde entre Zuheros y Cabra se alude a la presencia de los vértices de los cerros Cubilla de Zuheros o Cubilla de Cabra. En el deslinde entre Zuheros y Doña Mencía se incluyen los vértices del cerro de Los Castillejos, Las Lomas o de la Oreja de la Mula; a los que se unirá también la elección de la "Torre de Doña Mencía". Respecto al municipio de Carcabuey es el antológico Cerro del Lobatejo, vértice de primer orden, el que aparece como primordial punto focal de las mediciones ${ }^{22}$. En la línea de término de Baena son escasas las referencias de puntos claves. Por último, en el deslinde con el municipio de Luque, el topógrafo vuelve a hallar vértices topográficos de probada solvencia como el Cerro del Cabio, de Los Murciélagos o de Cotilla, a los que acompaña con algunas referencias a la "Torre de Luque", la "Torre de Zuheros" o ciertos caseríos y molinos del municipio de Zuheros (Figura 8).

En las "minutas planimétricas" de la localidad se recogen, como cabía esperar, la importancia de esos vértices. Pero también se incluyen, confirmando de nuevo el valor del poblamiento rural en la construcción cartográfica del último tercio del siglo XIX, una significativa colección de molinos, casas, cortijos y caseríos que habrán de favorecer las mediciones respecto a elementos longitudinales como las lindes de parcelas, cursos fluviales o caminos que atravesaban el municipio de Zuheros, o constituían marcas singulares en los deslindes de su jurisdicción territorial (Figura 8). Cortijos y molinos olivareros, casas-huerta y otro hábitat rural aparecen señalados como base de referencia y medición cartográfica. Algunos ejemplos de tales asentamientos fueron la casa-huerta de Cotilla de Juan León, la casa-huerta del Pilar, varios molinos aceiteros situados en las inmediaciones del río Bailón o el arroyo Cotilla, así como cortijos como el de Las Majadas, Los Mellados, del Navazuelo, de Manuel Uclé o de Francisco Camacho (Figura 8).

22 El Cerro del Lobatejo es el vértice más significativo de los referidos, pues pertenece a la red de primer orden de la triangulación nacional. Actualmente se le conoce como vértice Lobatejo II y presenta una altitud sobre el nivel del mar de 1.379,55 m. Por otro lado, como ocurre con otros puntos y cerros citados, cuenta con la particularidad de situarse en la parte más elevada de la Sierra de Cabra, coronando el cerro homónimo y en la propia linde de los términos de Carcabuey y Zuheros. 
Figura 8. Término de Zuheros en 1871-1872 y anotaciones realizadas en 1903 según las "minutas" planimétricas del Instituto Geográfico (1:25.000 en el original).

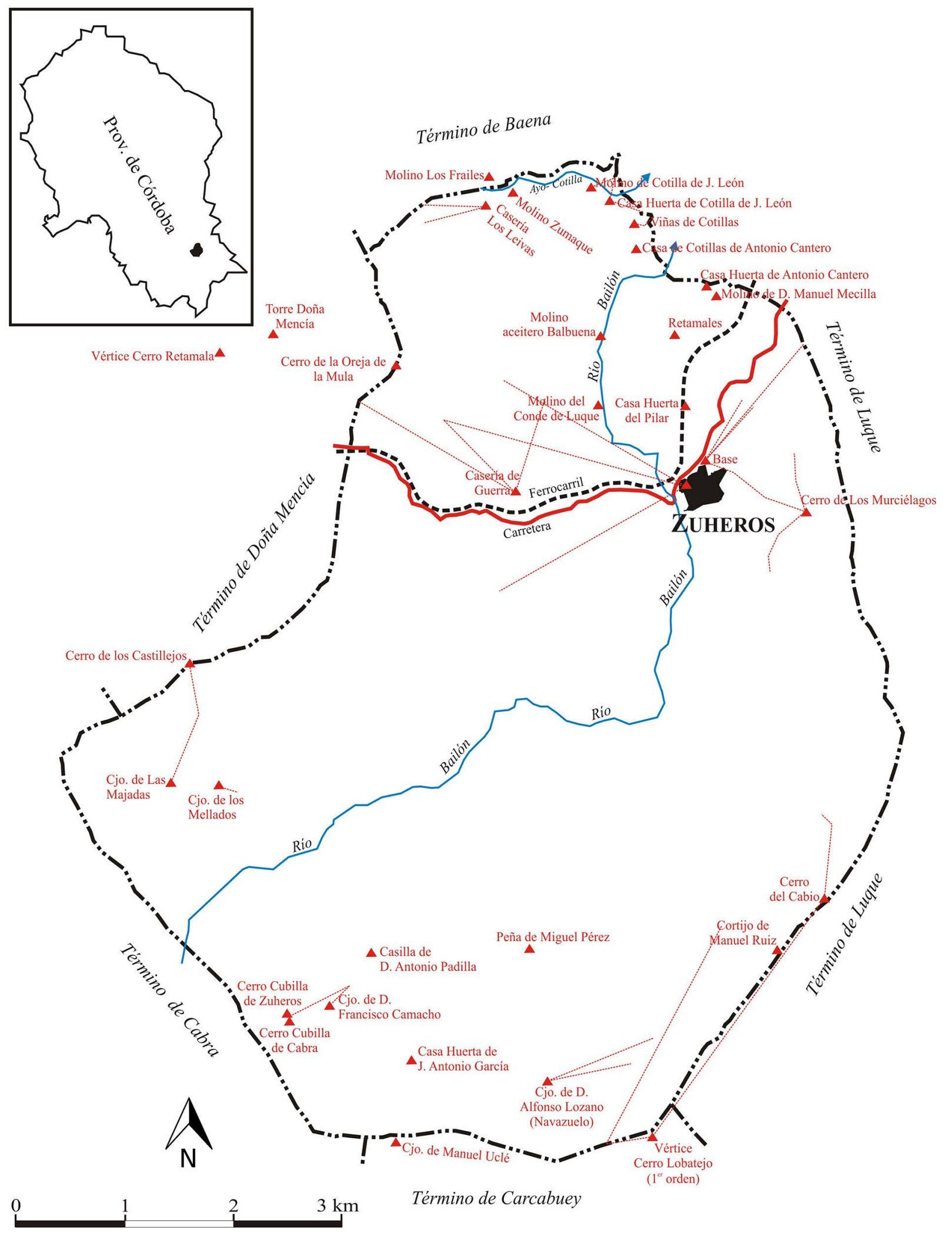

Fuente: Centro de Descargas del Archivo del IGN. Elaboración propia. 


\section{CONCLUSIONES}

El hábitat constituye uno de los pilares fundamentales de los paisajes rurales. Sus tradicionales funciones, materiales y expresiones tipológicas son, a la par, función de las variables naturales y humanas, y también parte consustancial de la construcción paisajística en la que se inscriben. Ese hábitat, en sus plurales expresiones y funciones, compendia el pasado y el presente de unos valores patrimoniales indiscutibles, unos valores que se sustentan tanto en la expresión tangible y material de sus edificaciones, como en los aspectos intangibles que a tales elementos se asocian en el pasado y en los nuevos principios neorruralistas.

En los términos cordobeses elegidos, sólo una aproximación inicial, hemos comprobado cómo a esos valores intrínsecos del hábitat rural hemos de sumar un hecho novedoso y poco estudiado hasta la fecha. Nos referimos al destacado papel que ese poblamiento, especialmente el diseminado, adquirió como instrumento y recurso cartográfico en la construcción de la primera serie del Mapa Topográfico Nacional 1:50.000 elaborado a finales del siglo XIX y principios del XX.

Las carencias técnicas y planimétricas, así como las limitaciones de la cartografía previa, obligaron a los topógrafos a recurrir al hábitat rural para establecer puntos visibles, estables y concretos desde los que trazar rumbos de orientación y mediciones topográficas. Caseríos, haciendas, cortijos, molinos e incluso chozos adquirieron el rango de vértices desde los que observar, medir y triangular el primer mapa topográfico de España. Bien configurando una red propia de construcciones con utilidad cartográfica, bien vinculando éstas con los relieves prominentes, adquieren especial relevancia las torres de comunicaciones o los emblemáticos campanarios parroquiales que despuntaban sobre los tejados de pueblos y villas.

De este modo, aunque con desigual presencia según las condiciones naturales y la densidad de poblamiento, las "minutas" cartográficas o los "cuadernos de líneas límite", herramientas previas y principales de la primera edición del Mapa Topográfico Nacional, abundan en el uso de ese hábitat rural como hitos de observación y cálculo de distancias. La presencia de elementos planimétricos naturales o humanos (ríos, caminos, lindes, carreteras, cercados, etc.) se vinculan al emplazamiento de antiguos molinos o cortijos, otorgando a éstos un valor añadido a su ya rica significación paisajística, social, económica o patrimonial. Un valor que se hace muy evidente con el análisis municipal que en el presente artículo presentamos y que se extiende al resto del territorio español, pues fue adoptada como una fórmula útil y adecuada para la construcción de esa primera expresión cartográfica de todo el territorio nacional. Circunstancia que, entre otras circunstancias, explica y justifica la propia riqueza toponímica y la abundancia planimétrica que la primera edición del Topográfico atesora respecto al poblamiento.

\section{REFERENCIAS}

Ager, J. (1977). Maps and Propaganda. Society of University Cartographers Bulletin, 11(1), 1-4.

Alcázar Molina, M. G. y Chica Palomo, Mª. D. (2011). El Instituto Geográfico y la cartografía catastral. Revista HP del Instituto Andaluz de Patrimonio Histórico (IAPH), (77), 37-38. Recuperado de http:// www.iaph.es/revistaph/index.php/revistaph/article/download/3094/3094

Almansa Pérez, R. Mª (1997). Oligarquía y regeneracionismo: demandas e iniciativas conservadoras desde la revista La Agricultura y Córdoba, del conde de Torres Cabrera (1900-1903). Revista de Historia Contemporánea, (8), 77-108. Recuperado de http://institucional.us.es/revistas/contemporanea/8/art_3.pdf

Almansa Pérez, R. Ma . (2008). Fraude fiscal y cuestión catastral entre finales del XIX y principios del XX: el ejemplo cordobés del Conde de Torres Cabrera. En R. Vallejo Pousada y A. Furió (Coord.). Los tributos de la tierra: fiscalidad y agricultura en España: Siglos XII-XX (pp. 597-616). Valencia, España: Servicio de Publicaciones de la Universidad de Valencia.

Capel, H. (1982). Geografía y matemáticas en la España del siglo XVIII. Barcelona, España: OikosTau.

Castañón, J. C. y Puyo, J. Y. (2008). La cartografía realizada por el ejército napoleónico durante la guerra de la Independencia. En F. Quirós y J. C. Castañón (Dir.). Madrid 1808- Guerra y territorio. Mapas y planos 1808-1814 (pp. 67-108.). Madrid, España: Edición del Museo de Historia.

Castañón, J. C., Puyo, J. Y. y Quirós, F. (2008). La herencia cartográfica y el avance en el conocimiento geográfico de España. En F. Quirós, y J. C. Castañón (Dir.). Madrid 1808-Guerra y territorio. Mapas y planos 1808-1814 (pp. 109-127). Madrid, España: Edición del Museo de Historia.

Claval, P. (1978). Espace et Pouvoir. Paris; France: Preses Universitaires de France. 
Córdoba de la Llave, R., Albendín, A., García, J. \& Ortiz, J. (2004). Puertos, azudes y norias. El patrimonio hidráulico histórico de Palma del Río (Córdoba). Sevilla, España: Fundación El Monte.

Cuadrado, J. G., y Peset, J. L. (1997). Metro y kilo: el sistema métrico decimal en España (Vol. 35). Barcelona, España: Ediciones Akal.

Feo Parrondo, F. (2002). El Catastro y otras fuentes complementarias para el estudio de la propiedad rústica española (1800-1940). Revista CT, (mayo 2002), 89-101. Recuperado de http://www.catastro. minhap.gob.es/documentos/publicaciones/ct/ct44/089-102.pdf

García-Badell Abadía, G. (1942). El catastro de la riqueza rústica en España. Madrid, España: Ministerio de Agricultura.

Hernando, A. (1996). El mapa de España, siglos XV-XVIII. Madrid, España: Ministerio de Fomento, Centro Nacional de Información Geográfica.

Lacoste, Y. (1977). La Geografía, un arma para la guerra. Barcelona, España: Editorial Anagrama.

López Ontiveros, A. (1981) (2 ${ }^{a}$ ed.). Evolución urbana de Córdoba y de los pueblos campiñeses. Córdoba, España: Excelentísima Diputación de Córdoba.

López Ontiveros, A. (1994). La agrociudad andaluza: caracterización, estructura y problemática. Revista de EstudiosRegionales, (39),59-92. Recuperadode http://www.revistaestudiosregionales.com/documentos/ articulos/pdf443.pdf

López Ontiveros, A., García Verdugo, F. R., Reyes Lorite, J. L. y Rivera Mateos, M. (1989). Bibliografía y fuentes para el estudio geográfico de la provincia de Córdoba. Axerquía. Revista de Estudios Cordobeses, (16), 53-157.

Martín Meras, Mª L. (1986). El Mapa de España en el siglo XVIII. Revista de Historia Naval, IV (12).

Metternicht, G. (2006). Consideraciones acerca del impacto de Google Earth en la valoración y difusión de los productos de georrepresentación. GeoFocus, (6), 1-10. Recuperado de http://geofocus.rediris. es/2006/Editorial_2006.pdf

Moral Ruiz, J. del, Pro Ruiz, J. y Suárez Bilbao, F. (2007). Estado y territorio en España, 1820-1930: la formación del paisaje nacional. Colección historia y paisaje. Madrid, España: Los Libros de la Catarata.

Moreno Jiménez, A. (2004). Nuevas tecnologías de la información y revalorización del conocimiento geográfico. Scripta Nova. Revista electrónica de Geografía y Ciencias Sociales, VIII, (170). Recuperado de http://www.ub.edu/geocrit/sn/sn-170-62.htm

Moreno Gómez, J. (1985). La Guerra civil en Córdoba: 1936-1939. Córdoba, España: Ed. Alpuerto.

Moya García, E., Cuesta Aguilar, M. J. y Sánchez Martínez, J. D. (2015). Los apuntes topográficos del Instituto Geográfico y Estadístico como fuente para el estudio del paisaje agrario: el ejemplo del olivar en la provincia de Jaén. En J. de la Riva, P. Ibarra, R. Montorio y M. Rodríguez (Eds.). Análisis espacial y representación geográfica: innovación y aplicación (pp. 1143-1152). Zaragoza, España: Universidad de Zaragoza y AGE.

Muñoz Dueñas, Má. D. y Mata Olmo, R. (1999). Fuentes y práctica catastral en Córdoba (siglos XVIIIXX): una reflexión desde la historia agraria. Revista Española de Estudios Agrosociales y Pesqueros, (185), 81-107. Recuperado de http://www.magrama.gob.es/ministerio/pags/biblioteca/revistas/pdf_ reeap/r185_04.pdf

Nadal, F. y Urteaga, L. (1990). Cartografía y estado: los mapas topográficos nacionales y la estadística territorial en el siglo XIX. Geocrítica, Cuadernos Críticos de Geografía Humana, XV (88). Recuperado de http://www.ub.edu/geocrit/geo88.htm

Naranjo Ramírez, J. (1991). La propiedad agraria en dos señoríos cordobeses: Fernán Núñez y Montemayor. Córdoba, España: Servicio de Publicaciones Universidad de Córdoba.

Naranjo Ramírez, J. (1995). Peculiar organización agraria de un señorío en la Campiña de Córdoba: Fernán Núñez". En Actas del II Congreso de Historia de Andalucía: Andalucía Moderna (pp. 139-149). Córdoba, España: Cajasur.

Naranjo Ramírez, J. (2001). El catastro de Ensenada en Córdoba: la operación piloto de Fernán Núñez. Boletín de la Real Academia de Córdoba de Ciencias, Bellas Letras y Nobles Artes, (140), 197-210. Recuperado de http://helvia.uco.es/xmlui/bitstream/handle/10396/5229/naranjol.pdf?sequence=1

Naranjo Ramírez, J. (2013). Las campiñas del Guadalquivir: claves para una interpretación geográfica. Revista de Estudios Regionales, (96), 99-134. Recuperado de http://www.revistaestudiosregionales. com/documentos/articulos/pdf1206.pdf 
Nuñez de las Cuevas, R. (1982). Cartografía española en el siglo XIX. En R. Núñez de las Cuevas, Historia de la Cartografía Española, Madrid, España: Real Academia de Ciencias Exactas, Físicas y Naturales.

Núñez de las Cuevas, R. (2005). El general don Carlos Ibáñez e Ibáñez de Ibero (1825-1891). En M. Cuesta Domingo y M. Alonso Baquer (Ed.). Militares y marinos en la Real Sociedad Geográfica. Madrid, España: Real Sociedad Geográfica.

Núñez de las Cuevas, R. (2012). El poder de los mapas. Estudios Geográficos, LXXIII (273), 581-598. Recuperado de http://estudiosgeograficos.revistas.csic.es/index.php/estudiosgeograficos/article/view/383/383

Orduña Rebollo, E. (2003). Nuevas aportaciones sobre el mapa municipal español. Revista de Estudios de la Administración Local (REAL), (291), 779-826.

Pajuelo, Mª J. (2008). La última esperanza: Peñarroya-Valsequillo, la batalla final de la República Española. Ibarra, Ecuador: Universidad Técnica del Norte.

Paladini Cuadrado, A. (1991). Notas para la historia del Mapa Topográfico Nacional de España. Militaria: Revista de Cultura Militar, (3), 83-100.

Pro Ruiz, J. (1989). Los orígenes del Catastro Parcelario de España. En Centro de Gestión Catastral (Ed.). El Catastro en España, de 1906 a la época actual (vol. 2, pp. 11-29). Madrid, España: Centro de Gestión Catastral.

Pro Ruiz, J. (1992). Estado, geometría y propiedad. Los orígenes del catastro en España. Madrid, España: Centro de Gestión Catastral.

Pro Ruiz, J. (1995). Ocultación de la riqueza rústica en España (1870-1936): acerca de la fiabilidad de las estadísticas sobre la propiedad y uso de la tierra. Revista de Historia Económica/Journal of Iberian and Latin American Economic History (Second Series), 13 (1), 89-114. Doi: http://dx.doi.org/10.1017/ $\underline{\mathrm{S} 0212610900004894}$

Puente Feliz, G. (1982). El sistema métrico decimal: su importancia y su implantación en España. Cuadernos de Historia Moderna y Contemporánea, (3), 95-126.

Quam, L. O. (1943). The use of maps in propaganda. Journal of Geography, 42 (1), 21-32. Doi: http:// dx.doi.org/ 10.1080/00221344308986602

Quirós, F, y Castañón J. C. (Dir.). (2008). Madrid 1808-Guerra y territorio-Mapas y planos 1808-1814. Madrid, España: Edición del Museo de Historia.

Sena, L. A. (1979). Unidades de las magnitudes físicas y sus dimensiones, Moscú, Rusia: Editorial Mir.

Torres Balbás, L. (1940). Las norias fluviales en España. Al-Andalus, (-), 192-208. Recuperado de http://oa. upm.es/34059/1/1940_norias_fluviales.pdf

Torres Márquez, M. y Naranjo Ramírez, J. (2012). El casco histórico de Córdoba y el primer plano de la ciudad: el Plano de los Franceses de 1811. Ería: Revista cuatrimestral de geografía, (88), 129-151. Recuperado de http://www.unioviedo.es/reunido/index.php/RCG/article/download/9664/9410

Torres Márquez, M. (2013). Paisajes del Valle medio del Guadalquivir cordobés: funcionalidad y cambios. Revista de Estudios Regionales, (96), 135-180. Recuperado de http://search.proquest.com/openview/d9 034f84504ac84c995e175f52181086/1?pq-origsite=gscholar

Urteaga, L. y Nadal, F. (2001). Las series del mapa topográfico de España a escala 1:50.000. Madrid, España: Centro Nacional de Información Geográfica.

Urteaga, L. y Capdevila, J. (2013). Tres hitos en el establecimiento de la red geodésica en Cataluña. Ería. Revista Cuatrimestral del Geografía, (93), 293-307. Recuperado de http://www.ub.edu/gehc/pdf/2013 Tres_hitos.pdf

Utrilla, P., Mazo, C., Sopena, M. C., Martínez-Bea, M. y Domingo, R. (2009). A palaeolithic map from 13,660 cal BP: engraved stone blocks from the Late Magdalenian in Abauntz Cave (Navarra, Spain). Journal of Human Evolution, 57 (2), 99-111. Doi: http://dx.doi.org/10.1016/j.jhevol.2009.05.005

Vázquez Maure, F. (1982a). Jorge Juan y la cartografía española del siglo XVIII. Boletín de la Real Sociedad Geográfica, (118), 127-140.

Vázquez Maure, F. (1982b). La primera hoja del Mapa Topográfico Nacional (Madrid, 1875). Boletín de la Real Sociedad Geográfica, (118), 157-170.

Wood, D. (1992). The Power of Maps. New York, USA: Guilford Press. 